Rhode Island College

Digital Commons @ RIC

2015

\title{
Overdose Education and Naloxone Distribution: Implementation in the Acute Care Setting
}

\author{
Emily A. Daniell \\ Rhode Island College
}

Follow this and additional works at: https://digitalcommons.ric.edu/etd

Part of the Other Nursing Commons

\section{Recommended Citation}

Daniell, Emily A., "Overdose Education and Naloxone Distribution: Implementation in the Acute Care Setting" (2015). Master's Theses, Dissertations, Graduate Research and Major Papers Overview. 144. https://digitalcommons.ric.edu/etd/144

This Major Paper is brought to you for free and open access by the Master's Theses, Dissertations, Graduate Research and Major Papers at Digital Commons @ RIC. It has been accepted for inclusion in Master's Theses, Dissertations, Graduate Research and Major Papers Overview by an authorized administrator of Digital Commons @ RIC. For more information, please contact digitalcommons@ric.edu. 


\section{OVERDOSE EDUCATION AND NALOXONE DISTRIBUTION:}

IMPLEMENTATION IN THE ACUTE CARE SETTING

by

\section{Emily A. Daniell}

A Major Paper Submitted in Partial Fulfillment

of the Requirements for the Degree of

Master of Science in Nursing

in

The School of Nursing

Rhode Island College

2015 


\begin{abstract}
The number of opioid related overdose deaths has increased significantly over the past ten years. In order to combat this problem, many drug treatment programs have implemented Overdose Education and Naloxone Distribution programs as a harm reduction technique. While these programs are fairly new, initial research demonstrated effective reduction in the number of opioid overdose related deaths. The risk of overdose deaths increases when an opioid addicted person is abstinent for a period of time and loses tolerance. Individuals who have been incarcerated, completed inpatient detoxification, or who have been admitted into an acute care setting face the risk of losing tolerance as a result of being opiate-free for a period of time. This decrease in tolerance significantly increases the risk of overdose when they resume using opioids. The purpose of this program was to develop and implement an educational program on the epidemic of opioid overdose and the safe administration of Naloxone by lay people. This program was aimed at Registered Nurses working on an inpatient medical/surgical telemetry unit within a small, academic medical center. A needs assessment was performed and a 20 minute educational program was offered during a scheduled staff meeting. Pre and post surveys based on knowledge content were collected and results were analyzed. Program evaluation was conducted in order to define the strengths and weaknesses of the developed program. Conclusions and implications for APRN practice were presented to the organization's Nurse Practice Council as well as Rhode Island College .
\end{abstract}

Keywords: opioid overdose, opioid overdose education, harm reduction, Naloxone 


\section{Table of Contents}

Background/ Statement of the Problem......................................... 1

Literature Review............................................................ 4

Theoretical Framework.......................................................... 11

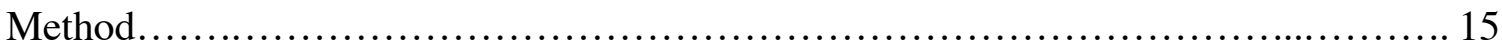

Results.................................................................... 23

Summary and Conclusions................................................... 29

Recommendations and Implications for Advanced Practice Nursing..................33

References.......................................................................

Appendices............................................................... 
Overdose Education and Naloxone Distribution:

Implementation in the Acute Care Setting

Background/Statement of the Problem

Opioid- related overdose has become an epidemic in the United States. In 2010, there were 38,329 drug overdose deaths; over 16,000 of those deaths were related to opioid analgesics (Centers for Disease Control and Prevention [CDC], 2014). In Rhode Island alone, there were 152 opioid related overdose deaths between November 2013 and March 2014 (CDC). These startling statistics have gained media attention after respected celebrities, such as Philip Seymour-Hoffman, also became victim to the epidemic.

Statistics show that men are a greater risk to die from opioid overdose than women. The Veteran population, comprised of nearly 86 percent men, is at even greater risk than the general population because of the predisposing factors that they bring to the table. Some of these predisposing factors include war-related injuries leading to chronic pain and being exposed to trauma events. The high incidence of Post-Traumatic Stress Disorder (PTSD) amongst Veterans could be considered factorial in their rates of drug use. In fiscal year 2013, the Veteran's Health Administration saw over 17,000 patients for opioid poisoning or other related encounters (United States Department of Veterans Affairs, 2014).

There are many myths surrounding opioid overdose. One of the most common myths is that heroin is the major player in the cause of overdose. However, between 1999-2009, the majority of drug overdose deaths involved opioid analgesics, Hydrocodone and Oxycodone being amongst the most prevalent (Bohnert et al., 2014). One must only quickly examine the top ten most prescribed medications in the United States to understand how this is occurring. Hydrocodone/Acetaminophen, also known as Vicodin, is represented three times in the top five most prescribed medications (Oliva, 2013). However, this is not to say that heroin users are immune to overdose. The recent influx of Fentanyl-laced heroin has been another contributing factor in the major increase 
in overdose deaths. Misuse of opioids of any kind can put an individual at risk. With an epidemic at hand, providers and clinicians had to act quickly to create a harm reduction strategy that could possibly save the lives of individuals who are at risk of overdose; prescribing Naloxone, an opioid antagonist or reversal agent, to high-risk individuals. In 1996, community substance abuse programs began implementing Overdose Education and Naloxone Distribution (OEND) programs in an attempt to prevent opioid overdoserelated deaths. OEND programs involved training individuals identified as being highrisk, how to recognize the signs and symptoms of opioid overdose and how to safely administer Naloxone in the event of a witnessed overdose. Preliminary program evaluations demonstrated that OEND programs were effective in reducing the number of deaths (Veterans Affairs Pharmacy and Benefits Management Services [VAPBM], 2014). Until recently, programs were scarce. It wasn't until the rise in overdose deaths started to become more evident that OEND programs became more widespread. Since then, there has been a large push to make Naloxone accessible to those suffering from opioid addiction. Nationally, Opiate Treatment Programs provided education their patients in an attempt to keep their patients safe.

Nurses are on the front lines of our healthcare system. Educating this population on the opioid overdose epidemic and increasing patients' access to Naloxone has the potential to reach an even greater number of at-risk individuals. The purpose of this project was to develop and implement an educational program, "Opioid Overdose Education and Naloxone Distribution: Train the Trainer," on the epidemic of opioid overdose and the safe administration of Naloxone by lay people such as, patients and their family members. The program served to educate medical-surgical nurses on how to better identify patients at risk for opioid overdose once they are discharged from the hospital. It also provided the nurses with the necessary knowledge to educate the patients and family members on how and when to administer Naloxone if they should experience or witness an overdose while in the community. 
Next there will be a review of relevant literature. 


\section{Literature Review}

A comprehensive review of the literature was completed. Research from the years 1996 to 2014 was extracted utilizing the search engines, CINHAL, Psych Info, and MEDLINE. The following key words were searched: opioid abuse, opioid overdose, overdose education, Naloxone, Naloxone distribution, peer education, and harm reduction. The following topic areas were discussed further: defining opioid overdose, harm reduction, Overdose Education and Naloxone Distribution Program: An Overview, overdose education and Naloxone distribution, and the Impact of Overdose Education and Naloxone Distribution programs.

Defining Opioid Overdose

Opioids, sometimes referred to as narcotics, are substances used for pain relief. Opioids are naturally found from the opium poppy, but can also be produced synthetically for example: Heroin, Oxycodone, Vicodin, Fentanyl as well as others (Veterans Affairs Palo Alto Health Care System (VA PAHCS, 2013). These aforementioned substances can be obtained both licitly, prescribed by a physician for pain relief, or illicitly, through the diversion of prescribed medication or production and selling of heroin. Opioids can be ingested by mouth, intranasally, transdermally, or intravenously. Opioid overdose, also commonly referred to as opioid poisoning, opioid intoxication, or opioid toxicity, is defined as a condition caused by the ingestion or absorption of opioids (CDC, 2013). Overdose from opioids occurs when there is too much drug for the body to handle. Overdose causes the brain to shut down the respiratory drive, which prevents the individual from breathing. Overdose happens as a gradual process approximately 1-3 hours after the drug has been taken. (VA PAHCS). The condition of opioid overdose is described by a set a clinical symptoms. Symptoms are caused by depression of the central nervous system and respiratory drive and can include alteration in respiratory status, alteration in level of consciousness, and pinpoint pupils (National Institute for Health [NIH], 2013). Opioid overdose is further broken down into 
cases of suspected, probable, or confirmed. Suspected overdose is defined as the evaluation of a patient by healthcare workers, which has not yet been supported by other credible evidence. Probable overdose occurs when there are high levels of suspicion, which can be connected with another case of overdose which has already been confirmed. Opioid overdose is classified as confirmed when both clinical evaluation and laboratory testing are consistent (CDC, 2014).

Harm Reduction

Harm reduction, as defined by Tatarsky and Marlatt (2010), is a framework for addressing substance use and other potentially risky behaviors, which aims to reduce the harmful consequences of these behaviors without requiring abstinence as a goal or a prerequisite for treatment. The approach involves the acceptance that the individual may continue to use substances, but that the risks to the individual and the community are significantly decreased by implementing said harm reduction measures. Examples of harm reduction approaches include needle exchange programs for intravenous heroin users, medication assisted treatment programs for opiate addicts, and most recently, Naloxone distribution to the at-risk population. According to Tartarsky \& Marlatt, harm reduction encompasses a "human rights agenda" (p.117) by providing treatment to marginalized populations and "is based on a deep appreciation of the uniqueness for each patient's journey" (p.118). Harm reduction saw its origins in Europe in the 1970s and 1980s. It was during the discovery of the HIV/AIDS epidemic that harm reduction made its way to the United States (Tartarsky \& Marlatt, 2010).

Harm reduction is still considered to be widely controversial and often unsupported by the federal and state governments as well as many clinicians. Changes in governmental approach to the treatment of substance abusers have brought about more support of late. These changes include substance abuse treatment rather than incarceration, the recognition that substance abuse is often a comorbid condition with other mental health problems, and the push for evidence based practice (Tartarsky \& 
Marlatt). Marlatt, Larimer, \& Witkiewitz (2012) suggested that harm reduction should not only protect the individual but should have more widespread effects such as changes in local policy and decriminalization at the local level. In 2012, the State of Rhode Island and Providence Plantations implemented the Rhode Island Good Samaritan Overdose Prevention Act. The act is a first-hand example of harm reduction strategies effecting local policy change. The act prevents any person who has called emergency services because of a witnessed drug overdose from facing criminal drug changes. Rhode Island is joined by 14 other states in enacting this type of legislation (Drug Policy Alliance, 2014). Overdose Education and Naloxone Distribution Programs: An Overview

Overdose Education and Naloxone Distribution programs first began in 1996 within community based substance abuse harm reduction programs (VA Pharmacy Benefits and Management Services, 2014). In 2007, the year after Boston and Cambridge implemented OEND programs at local public health agencies, the Massachusetts Department of Public Health began to expand OEND offerings (Doe-Simkins et al., 2014). Programs are now offered around the country in a variety of different settings. Some OEND programs provide teaching to drug users on an individual basis and others offer group education. Various curricula have been developed by agencies such as the Harm Reduction Coalition, the Chicago Recovery Alliance, and the Drug Overdose Prevention and Education project (Doe-Simkins et. al, 2014). The curriculums target substance abusers, physicians, and first-responders (Beletsky, Rich, \& Walley, 2012). Some programs provide intramuscular Naloxone rescue kits, while others offer intranasal rescue kits (Wilder et al., 2014). Kits universally include two doses of Naloxone and educational instructions. Intramuscular kits usually include alcohol pads and gloves. Many programs also include face shields to provide rescue breathing (Doe-Simkins, et al.). Research has shown no significant difference in the effectiveness of intramuscular versus intranasal Naloxone, but there have been studies that show that intranasal Naloxone kits are more cumbersome and difficult for lay people to use. Intranasal 
Naloxone sometimes requires additional doses, may have a slower onset of action, and may have lower bioavailability than intramuscular Naloxone (VA PBM, 2014).

A trained medical professional usually provides the educational offerings. Subject content includes how to recognize the signs and symptoms of opioid overdose, the importance of seeking help, the proper technique for rescue breathing, and the safe administration of Naloxone (Doe-Simkins, et al.). Participants receive education on how Naloxone works to reverse opioid overdose and instructions on if the individual has overdosed with long acting opiates, such as Fentanyl, an additional dose of Naloxone may be required as opioids typically have a longer half-life than Naloxone, so it is possible for individuals to fall back into an overdose as the Naloxone wears off.

Overdose Education and Naloxone Distribution programs have become more widespread throughout the United States in the face of the opioid overdose epidemic. While program content remains consistent amongst programs, methods for patient education vary. The route of Naloxone administration also varies amongst programs as provider preference or access to the medication contribute to which type of Naloxone the patients are given. OEND programs have been shown to be effective in reversing opioid overdose and preventing overdose-related death (Oliva, 2014). Impact of Overdose Education and Naloxone Distribution

The majority of research on the effectiveness of OEND is currently measured through program evaluation. Because OEND has only recently become widespread, there are few systematic reviews available. However, initial research has shown that programs have been effective in reducing the number of fatal overdose deaths.

Walley et al (2013), sought to evaluate the OEND programs implemented in Massachusetts. The evaluation was done by performing a time series analysis of the 19 communities that had implemented OEND. Researchers looked at fatal opioid overdose rates before and after OEND programs had been implemented as well as acute care hospital utilization rates for opioid overdose in each community. Results yielded 327 
reversed opioid overdoses. The study also found that overdose rates had decreased approximately $73 \%(\mathrm{p}<0.01)$ in the 19 studied Massachusetts's communities and that OEND is an effective intervention in the face of the opioid overdose epidemic.

Williams, Marsden, and Strang (2013) sought to research the differences in knowledge and attitudes about opioid overdose in family members of heroin users. The study consisted of two groups, one receiving OEND training and one group that did not. Prior to the education, both groups reported similar knowledge and attitudes about opioid overdose. Following the intervention, the group who received OEND training not only had $35 \%$ of participants show increased knowledge about overdose, but $54 \%$ of participants also demonstrated more positive attitudes. Results also showed that the group who received OEND retained the information six months following the study.

Green, Heimer, and Grau (2008) were some of the first researchers to look at early OEND programs throughout the United States. They evaluated six programs around the country. Programs were based in Baltimore, San Francisco, Chicago, New York, and New Mexico. Ten participants (heroin users) from each site were recruited to complete a survey testing their knowledge of OEND. Participants were divided into groups of those who had been trained in OEND and those who had not. They were given 16 scenarios and asked whether an overdose was occurring and whether Naloxone administration was indicated. The participants were primarily male and the majority had witnessed an opioid overdose in the past. Results from the study found that individuals who were trained in OEND were more competent at recognizing overdose scenarios as well as identifying when Naloxone was indicated. Trained individuals scored $82.5 \%$ competency in recognizing overdose symptoms versus only $63 \%$ competency in the untrained individuals. Results also demonstrated that trained individuals were just as competent as trained medical professionals in recognizing overdose and when Naloxone was indicated. Both medical experts and trained individuals appropriately assigned approximately $45 \%$ of the scenarios to the opioid overdose category. 
Although research was not abundant, evidence has shown that implementing OEND programs can be effective in reducing harm and decreasing overdose related deaths. Individuals who received training were more informed and have increased knowledge, which provides further evidence for the implementation and continuation of the programs. Research did not differentiate amongst who were the most effective trainers, but with nurses being at the bedside, there was an increase in access to patients and their families, which provided ample opportunities for patient teaching. 
W.K. Kellogg's Logic Model

This OEND: Train the Trainer program was developed using W.K. Kellogg Foundation's program logic model. According the Logic Model Development Guide (2004), the logic model is "a conscious process that creates an explicit understanding of the challenges ahead, resources available, and the timetable in which to hit the target" (p.1). The model provided a visual guide for investors to understand what benefit will come from the program.

The model consisted of two main portions: planned work and intended results. Within planned work, both resources and program activities were considered. Resources, or inputs, included manpower needed to implement the program, the time involved and cost of the time, financial investment placed, and the resources available within your organization. Planned activities consised of all of the tools and measures put into place to bring about change. Such actives include the "how" of your implementation. How will the desired effect come about? For example, what tools will you use and how will you present the material? (W.K. Kellogg Foundation, 2004). The second piece of the model involved examining the outputs from the planned activities. What came out of the planning stage? What are the outcomes and how did those outcomes make an impact? Figure 1 provides a visual diagram of how the model works from start to finish.

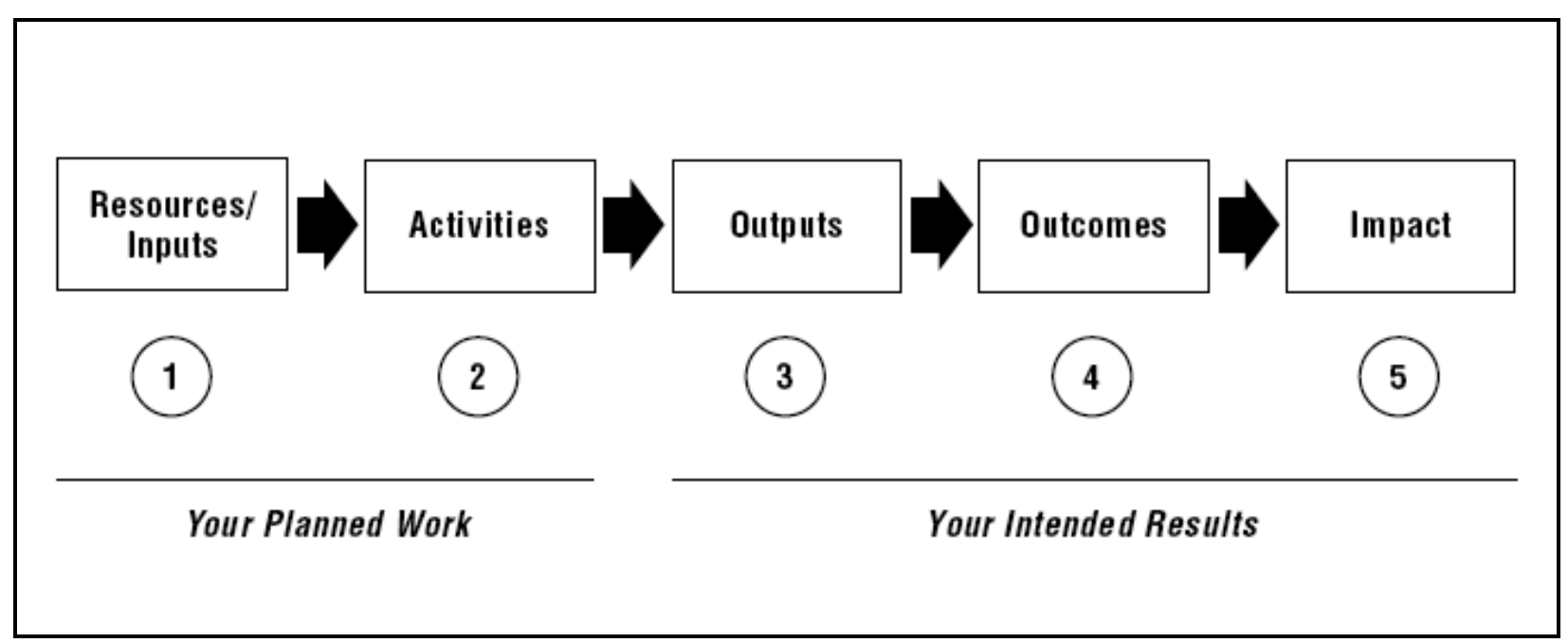

Figure 1. 


\section{W. K. Foundation Basic Logic Model}

Following the definition of planned work and intended results, there are three main steps involved in developing a program: planning and design, implementation, and evaluation. Ideally, these three steps are a constantly evolving process utilized to continually improve the quality of the program.

\section{Knowles' Theory of Adult Learning}

The content development, or planned activities, of this program were constructed utilizing Knowles' Theory of Adult Learning, a model of assumptions about learners (Knowles, 1970). Knowles states that when teaching adults, the educator must account for the predisposing factors that the adult learner brings to the table. He addressed assumptions about the adult learner and uses those assumptions to make practice implications.

Knowles identified five practice implications that the teacher or educator must consider to effectively teach adult learners. The first issue that Knowles addressed was ensuring that the "learning climate" is conducive and comfortable for students. Students should be both physically comfortable in the environment, but they must also be psychologically at ease. The learning climate included the manner in which the educator presents himself as the adult learner is often dissuaded by judgment from other adults. Knowles also suggested that a "diagnosis of needs" be performed that involves defining the required competencies and allowing the learner to assess their knowledge both before and after the education takes place. After the learners' needs have been identified, the planning process should take place. Knowles stressed the importance of allowing learners to be involved in the process of their learning. The educator must then utilize the planning to promote learning. Educators must act more as resources than formal educators. Students should be self-directed in their learning. The final implication is selfevaluation. Knowles stressed the importance of providing ways to allow the students to 
evaluate their progress. He addressed the usefulness of the needs diagnosis in measuring learning progress (Knowles, 1970).

Both of these models were used to develop this program. The Logic Model was utilized in the planning stage, which will be described in more detail in the following section, and Knowles' theory was considered when planning how to carry out the education. Because Knowles also stressed the importance of a needs assessment, a four phase needs assessment was also done.

In order to appropriately identify educational needs of the RNs, the Four Phase Needs Assessment Model was followed. The goals focused on educating RNs on the epidemic of opioid overdose and increase RN knowledge base on OEND content. To determine whether the goals were being met or how well they were being met, a preintervention survey (Appendix $C$ ) was performed. The next step of the needs assessment was to analyze the results of the pre-intervention survey and determine the gaps in knowledge. Percentages were used to determine how RNs scored on each particular question. The final phase of the educational needs assessment was to set priorities of the teaching to occur. The data from the gap assessment was utilized to determine which content areas need more focus than others. The data helped to construct the content of the teaching and ensure that the educational goals were met. This phase also involved determining the consequences of the goals not being met and identifying the cost of the resources that were needed to meet the educational goals (SUNY, 2014). 


\section{Method}

Purpose

The purpose of this project was to develop and implement an educational program for registered nurses on the epidemic of opioid overdose and the safe administration of Naloxone by opioid addicts and their family members.

Design

The design of this study consisted of a pre survey, intervention, post survey. Prior to the educational program being offered, a Survey Monkey® questionnaire was administered to participants. The survey was available for completion until the day before the education was offered. Participants who attended the educational program were then asked to complete an identical post-education questionnaire.

Participants

Participants for this program were Registered Nurse employees of a 27 bed medical/surgical telemetry unit at the Veteran's Affairs Medical Center. Ideally, the education was to reach at least $50 \%$ of the 27 Registered Nurse employed on the medicalsurgical floor.

Site 
The site of this program development was the Providence Veteran's Affairs Medical Center (PVAMC). The PVAMC is a small, academic medical setting treating Veterans of the United States Armed Forces. The site contains 77 acute care beds. Approval

Approval was obtained from the Institutional Review Board at the PVAMC as well as Rhode Island College.

Planning

Program Development: Logic Model

Logic Model/Planning and Needs Assessment. A needs assessment was conducted to establish evidence of the problem and determine educational needs of the registered nurses on the identified unit. Burton \& Merrill (1991) identified four phases of a needs assessment. These four phases were to: list goals, determine whether or how well the goals are being achieved, determine gaps between desired and actual performance, and setting priorities.

The needs assessment began as the opioid overdose epidemic dramatically increased. Overdose numbers began to increase both locally and nationally. The increase in incidents prompted a local call for action. At the same time, the Veteran's Health Administration (VHA) issued a directive for all VHA facilities to implement OEND programs to prevent opioid overdose deaths from occurring. The PVAMC proposed a pilot program to implement an OEND program within the Opiate Treatment Program (OTP). An informal committee consisting of the Chief of Primary Care, Chief of Pharmacy, OTP medical staff, OTP Lead Nurse (this researcher), and Interventional Pain Clinic medical staff met to define the goals of the program and to determine the logistics of who would be eligible to receive a Naloxone Kit, who would be ordering the kits, who would be providing the education to patients, and how the program would expand past the pilot. A formal proposal was submitted to the Pharmacy and Therapeutics (P\&T) 
committee. The P\&T committee addressed the logistics of ordering Naloxone rescue kits and further defined the process by which patients would be educated.

Once the pilot program was successfully initiated, the question arose as to whether similar programs would be beneficial in other services around the medical center. The VHA issued Interim Recommendations for the VA Overdose Education and Naloxone Distribution Program (Appendix A: OEND Interim Guidelines) (Department of Veterans Affairs, 2014). The recommendations highlighted populations that would benefit from OEND. Patients admitted for inpatient opiate withdrawal management were identified as a "direct association with benefit" population. The researcher, the Nursing Excellence and Evidence Based Practice Coordinator, the Performance Improvement Coordinator, and the Chief of the Health Information Management System worked together to identify the number of patients seen for withdrawal management in Fiscal Year 2013 (FY13). Patients were identified by isolating ICD-9 codes 304.00 opioid type dependence, unspecified. In FY13, the PVAMC treated 135 patients for opioid dependence on an inpatient basis. With this in mind, the team determined that there was a sufficient need to implement an OEND pilot program on one of the inpatient units. The program consisted of the researcher educating the Registered Nurses of an identified medical-surgical telemetry floor on the opioid overdose epidemic and the safe administration of Naloxone by patients and family members in the event that they witness an opioid overdose.

Logic Model: Program Design and Planning

The content of this project was determined from the outcomes of the needs assessment, the review of the relevant literature, and the collaboration of the Chief of Nursing, the Nurse Excellence Coordinator, the Clinical Nurse Leader (CNL), the Medical/Surgical unit Nurse Manager, and the researcher.

The first steps of program design involved the planned work, which included identifying necessary resources, and planned activities. Resources identified were the 
staff members needed to implement the program. All of the aforementioned staff members were considered resources for the project, but the researcher would be the individual to offer the education. Other resources included time devoted to the project, time given by the participants of the program, space to implement the project, necessary materials i.e. a trifold poster, paper, and computer access. Planned activities involved identifying the objectives of the program and how they would be met. The learning objectives of the program included understanding the opioid overdose epidemic, recognizing risk factors for opioid overdose, recognizing signs and symptoms of opioid overdose, understanding when and how to safely administer Naloxone, and the importance of accessing immediate medical attention in the case of witnessed overdose.

The content objectives were utilized to construct a PowerPoint program containing relevant information. The PowerPoint program included recent local and national opioid overdose statistics as well as visual aids to support those statistics. The program also included OEND materials that were already being used for patient education within the facility. The patient education materials included information on how to prevent opioid overdose, information about the medication Naloxone, how to recognize signs and symptoms of an overdose, and how to react in the case of a witnessed overdose. Participants were taught the acronym NARC 9-1-1 to remember the necessary steps to take in the event of a witnessed opioid overdose. NARC 9-1-1 stands for Naloxone, Airway, Rescue breathing, and Call 9-1-1. Each of those steps was elaborated upon to promote learning and understanding. All of the information was also reinforced on a trifold poster that was left in the conference room of the inpatient floor so that nurses could utilize the information as a refresher prior to providing patient education. Procedures

Approval was first sought from the PVAMC administration. After receiving approval from the Nurse Excellence Coordinator and Nurse Executive, IRB approval was sought and obtained from both the Providence Veterans Affairs Medical Center and 
Rhode Island College. Upon IRB approval, registered nurses on the designated medicalsurgical floor received an informational email (Appendix B: Informational Email) informing them of the project, the project timeframe, and asked for their participation in the pre and post surveys. Prior to the educational program being offered, a preintervention survey (Appendix C: Pre-survey) of content knowledge was offered using Survey Monkey®. RNs were able to provide informed consent through the Survey Monkey® software.

Intervention

A 20 minute educational class was provided to each of the three different shifts. The educational program consisted of a 20 -minute teaching which was offered a total of three times. Educational sessions were held at 04:30, 11:00, and 19:00 in attempts to accommodate nurses working each shift. The program included a PowerPoint presentation educating participants on the epidemiology of opioid overdose, risk factors for opioid overdose, and OEND materials and procedure for patient education. Following the program, a post-intervention survey (Appendix C: Post-survey) was offered on Survey Monkey®. Educational brochures were left in the unit conference room to reinforce learning. The RNs were provided with the contact information of the OTP Lead $\mathrm{RN}$ in the case of further questions. The OTP Lead RN worked closely with the CNL to ensure that staff education remained up-to-date.

\section{Measurement}

A survey was developed by Traci Green (2006) and was utilized and adapted, with her permission, for the purposes of this study. The Brief Overdose Recognition Response Assessment (BORRA) was originally developed for patients or individuals using opioids in the clinic setting. It has since been used to measure OEND training objectives for caregivers, prisoners, police and fire officials, and pharmacists. The survey offered sixteen different scenarios and asked the participant to answer either "Definitely or probably not an opiated OD," "An OD but definitely NOT an opiate OD (for example, 
cocaine intoxication),", "Not signs of an overdose," or "Unsure/not enough info." In each scenario, participants were also asked whether or not Naloxone should be administered. Items were then scored with either a " 1 " or " 0 " depending on the appropriate answer. Correct answers were calculated out of 16 and divided to get a percentage correct, which would demonstrate overdose and naloxone administration knowledge.

The survey had historically been administered via pencil and paper, but was adapted into an electronic survey through Survey Monkey® (Appendix D: Brief Overdose Recognition Response Assessment). Registered Nurses employed on the designated floor were asked to participate in the survey, which they completed online. Both pre and post surveys were identical. Adaptations from the original survey included removing the answer option "an overdose but definitely not an opiate overdose" as well as removing two of the redundant items, making this a fourteen item questionnaire. This particular program focused solely on the ability to recognize signs and symptoms of opioid overdose. It was unnecessary to be able to distinguish or recognize overdose of other substances.

Data was measured following the completion of the return of the post-intervention surveys. Means were calculated to determine whether RNs knowledge of OEND increased for each item in question. The difference in means provided insight into whether or not nurses gained knowledge on how to recognize signs of opioid overdose and whether or not to administer Naloxone.

Time Frame

Permission was first granted from the EBP Coordinator and Nurse Manager to implement the project. IRB approval was obtained from the Providence VAMC in January 2015 and from Rhode Island College in March 2015. The SurveyMonkey® preeducation questionnaire was rolled out on March 17, 2015. The pre-education questionnaire was open for a period of three months to allow for appropriate response 
time. The educational sessions were offered during the last week of July. The posteducation questionnaire was offered the day after the education was completed and was open for approximately two weeks. Data analysis occurred during August and September. The results and final paper would be ready for presentation in December. Ethical Concerns

Potential ethical concerns for the project were that nurses are often considered a vulnerable population and therefore must be provided a higher level of protection. All participants gave informed consent prior to participating in the study. Another area of concern was the content of the education. Overdose Education and Naloxone Distribution is a harm reduction approach, which is often considered a controversial approach, however; the project only focused on educating nurses on how to provide the education. Participants did not include patients and/or family members of patients diagnosed with opioid abuse.

Logic model: Program Evaluation

Following the completion of the project, program participants were given the opportunity to evaluate the program. A program evaluation tool (Appendix E: Program Evaluation) constructed by the VHA was utilized to assess if participants considered goals having been met. Questions were answered on a Likert-type scale. RNs were also provided with the opportunity to provide recommendations for change or identify strengths of the current program. 
Results

Results from data analysis will be discussed in this section. Demographics

To protect anonymity in such a small learning facility, no specific demographic data were collected. There were 21 out of 27 (77\%) potential participants who completed the pre-education questionnaire (pre-test) and 15 out of 27 (56\%) who completed the post-education questionnaire (post-test). All participants were employed on the medicalsurgical floor.

Pre/Post Survey Results

Prior to the education being offered, an email was sent out to the RNs employed on the floor where the project was taking place. The email provided a link to the preeducation survey as well as dates and times that the education would be offered. There were 21 RNs who participated in the pre-education survey. After the education was offered, RNs were provided a link to the post-survey. Out of the 21 original participants, 15 RNs completed the post-education survey. Results were broken down into two categories: items containing scenarios consistent with symptoms of opioid overdose/ administer Naloxone and items inconsistent with opioid overdose/ do NOT administer Naloxone. Means were gathered from respondents for both the pre-test and post-tests for each item. Means were broken down both by individual question as well as overall difference in pre and post-test scores. For questions containing symptoms consistent with signs of opioid overdose mean scores improved from $69 \%$ to $84 \%$, demonstrating an increase in knowledge gained. Means for questions containing symptoms inconsistent 
with symptoms of opioid overdose demonstrated a decline in scores between the pre and posttests. Prior to the education being offered, $68 \%$ of respondents answered the questions correctly. After the education, only $63 \%$ of respondents answered questions correctly. Explanations for these changes are discussed in the following section. The following tables demonstrate the mean differences for each invidiual question. Table 1.1 illustrates the results of the pre and post tests for items consistent with symptoms of opioid overdose and Table 1.2 illustrates the results for items inconsistent with symptoms of opioid overdose.

Table 1 Results for items consistent with symptoms of opioid overdose 


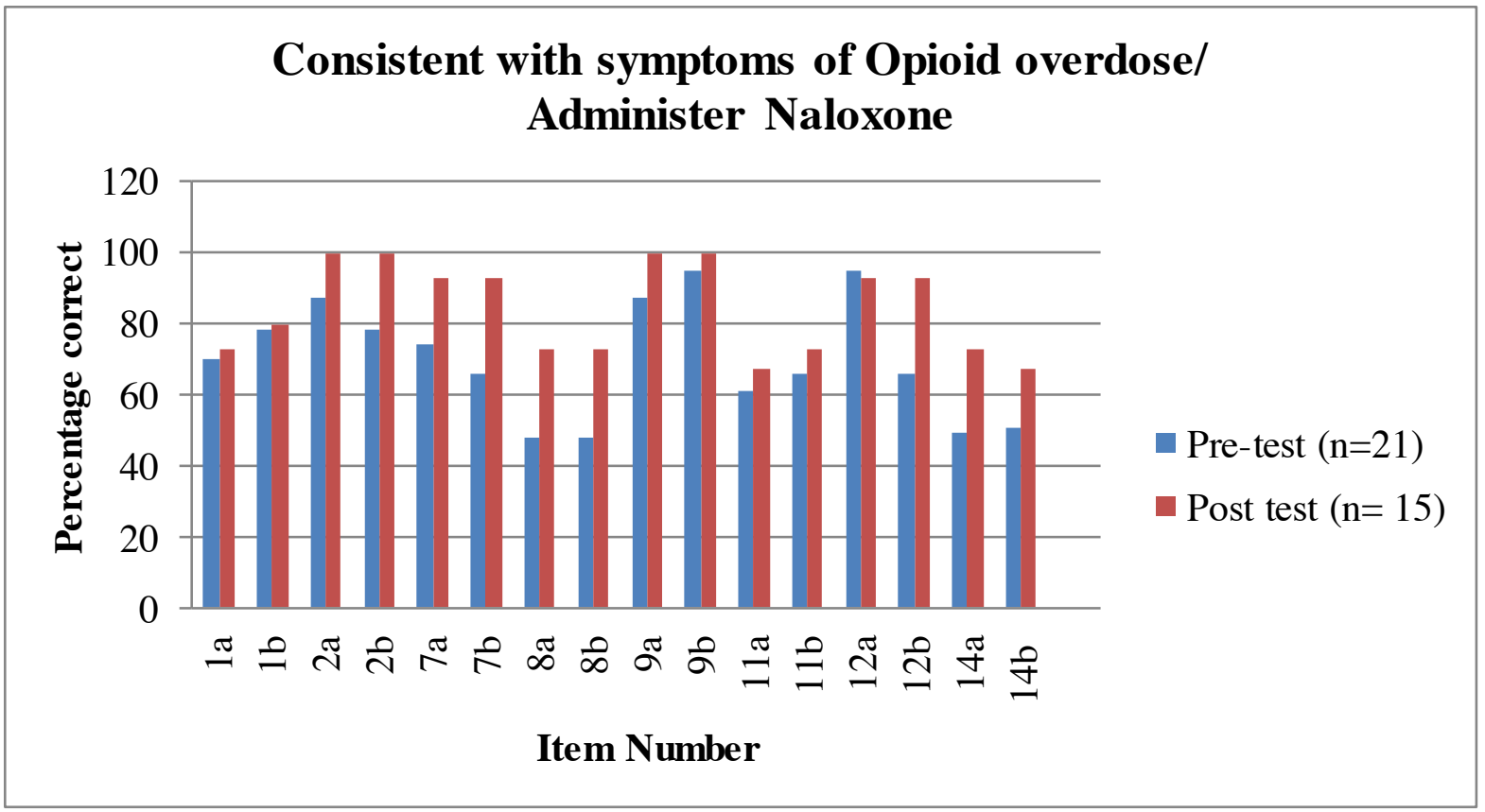

Table 2 Results for items inconsistent with symptoms of opioid overdose

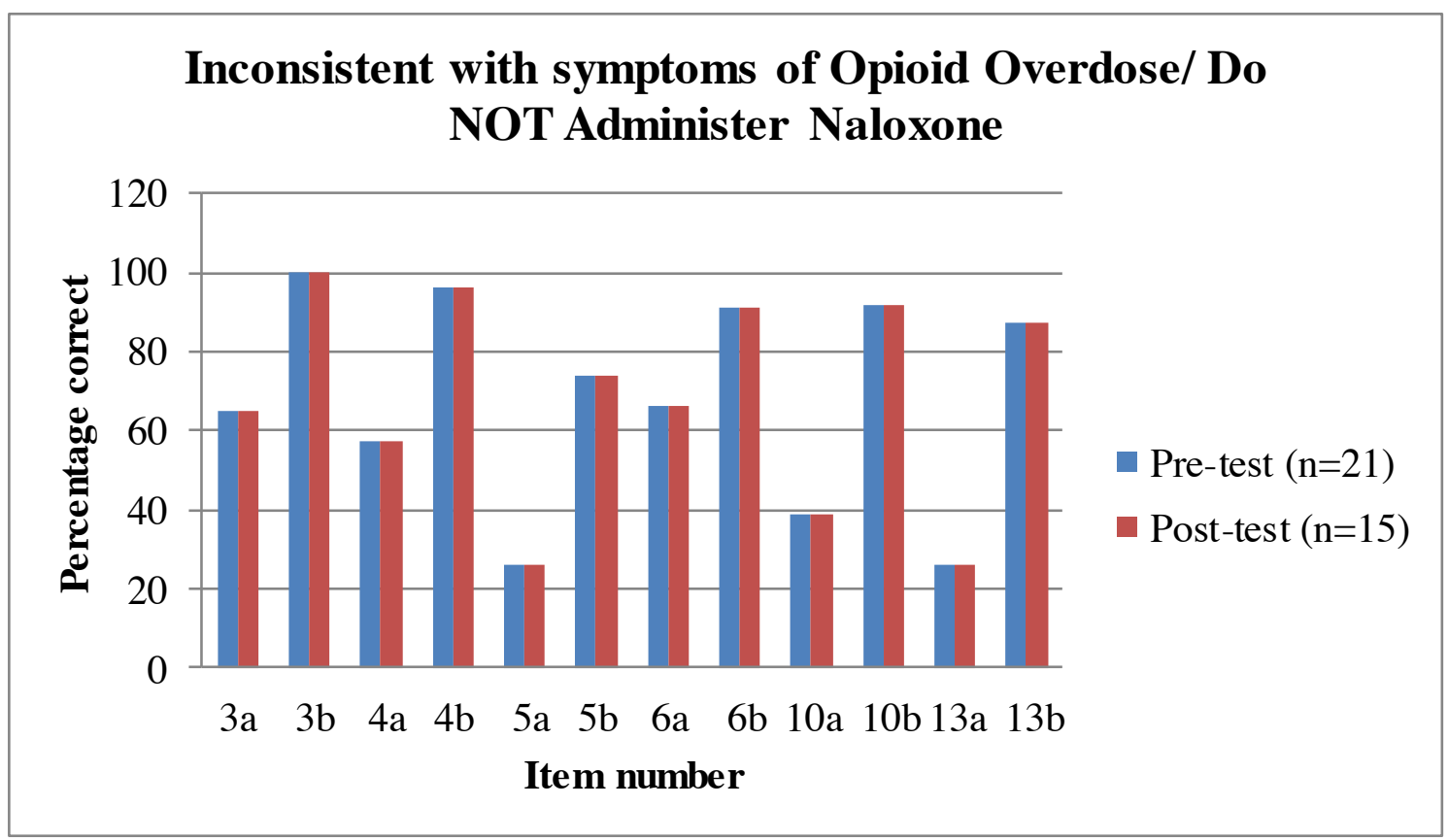

Program Evaluation 
A program evaluation was offered following the completion of the education. Participants had the opportunity to provide feedback on the education and any suggestions that they may have for improvement. A standard evaluation form measuring the objectives of the education were met and how well they were met as well as the effectiveness of the presenter, was offered to participants who completed both the pre and post questionnaires (Appendix F: Program Evaluation).

The evaluation was broken down into two different sections. The first section was based on a 4-point Likert scale and asked participants to rate the effectiveness of the presenter in meeting the educational objectives. The second section, which was also based on a 4-point Likert scale with slightly different options than the first, asked participants to rate how well the speaker presented the information. In 3 out of 4 items in the first section, respondents answered "4-Completely met". In the item "Describe the sources for Patient Education and identify notes required for documentation" one respondent answered "3- Mostly met." Similar results were found in the second section of the evaluation. All respondents either answered "4-Excellent" or "3-Very good" for all five items. The results are displayed in the tables 3 and 4, which are found below.

Table 3 Program Evaluation, Objectives Met

\begin{tabular}{|c|c|c|c|c|c|}
\hline Learning Objective & Mean Score & $\begin{array}{l}\text { Completely Met } \\
\text { (4) }\end{array}$ & $\begin{array}{l}\text { Mostly } \\
\text { Met } \\
\text { (3) }\end{array}$ & $\begin{array}{c}\text { Partially } \\
\text { Met } \\
\text { (2) }\end{array}$ & $\begin{array}{c}\text { Did } \\
\text { Not } \\
\text { Meet } \\
(1)\end{array}$ \\
\hline \multirow[t]{2}{*}{$\begin{array}{c}\text { Discuss the Epidemiology } \\
\text { of Overdose. }\end{array}$} & \multirow{2}{*}{4.0} & 15 & 0 & 0 & 0 \\
\hline & & $100 \%$ & $0 \%$ & $0 \%$ & $0 \%$ \\
\hline
\end{tabular}




\begin{tabular}{|c|c|c|c|c|c|}
\hline \multirow[t]{2}{*}{$\begin{array}{l}\text { Describe the eligibility for } \\
\text { Naloxone kits. }\end{array}$} & \multirow{2}{*}{4.0} & 15 & 0 & 0 & 0 \\
\hline & & $100 \%$ & $0 \%$ & $0 \%$ & $0 \%$ \\
\hline \multirow[t]{2}{*}{$\begin{array}{l}\text { Explain the process for } \\
\text { order and prescriptions. }\end{array}$} & \multirow{2}{*}{4.0} & 15 & 0 & 0 & 0 \\
\hline & & $100 \%$ & $0 \%$ & $0 \%$ & $0 \%$ \\
\hline \multirow{2}{*}{$\begin{array}{l}\text { Describe the sources for } \\
\text { Patient Education and } \\
\text { identify notes required for } \\
\text { documentation. }\end{array}$} & \multirow[b]{2}{*}{3.9} & 14 & 1 & 0 & 0 \\
\hline & & $94 \%$ & $6 \%$ & $0 \%$ & $0 \%$ \\
\hline
\end{tabular}

Table 4 Program Evaluation, Presenter and Teaching Strategies

\begin{tabular}{|c|c|c|c|c|c|}
\hline & Mean Score & $\begin{array}{c}\text { Excellent } \\
(4)\end{array}$ & $\begin{array}{c}\text { Very } \\
\text { Good } \\
(3)\end{array}$ & $\begin{array}{c}\text { Satisfactory } \\
(2)\end{array}$ & $\begin{array}{c}\text { Poor } \\
(1)\end{array}$ \\
\hline $\begin{array}{c}\text { Speaker's expertise } \\
\text { contributed to the } \\
\text { accomplishment of the } \\
\text { learning objectives }\end{array}$ & $\mathbf{4 . 0 0}$ & $\mathbf{1 5}$ & $\mathbf{0}$ & $\mathbf{0}$ & $\mathbf{0}$ \\
\cline { 3 - 6 } & $\mathbf{1 0 0 \%}$ & $\mathbf{0 \%}$ & $\mathbf{0 \%}$ & $\mathbf{0 \%}$ \\
\hline $\begin{array}{c}\text { Teaching } \\
\text { strategies/learning } \\
\text { methods were utilized } \\
\text { effectively }\end{array}$ & $\mathbf{3 . 8 6}$ & $\mathbf{1 3}$ & $\mathbf{2}$ & $\mathbf{0}$ & $\mathbf{0}$ \\
\cline { 3 - 6 } & & $\mathbf{8 7 \%}$ & $\mathbf{1 3 \%}$ & $\mathbf{0 \%}$ & $\mathbf{0 \%}$ \\
\hline $\begin{array}{c}\text { Instructional materials } \\
\text { \&/or handouts were }\end{array}$ & & $\mathbf{1 4}$ & $\mathbf{1}$ & $\mathbf{0}$ & $\mathbf{0}$ \\
\hline
\end{tabular}




\begin{tabular}{|c|c|c|c|c|c|}
\hline $\begin{array}{c}\text { available and supported } \\
\text { the teaching methods }\end{array}$ & $\mathbf{3 . 9 3}$ & $\mathbf{9 3 \%}$ & $\mathbf{7 \%}$ & $\mathbf{0 \%}$ & $\mathbf{0 \%}$ \\
\hline $\begin{array}{c}\text { The content \& objectives } \\
\text { are appropriate and } \\
\text { relevant to your practice. }\end{array}$ & $\mathbf{3 . 9 3}$ & $\mathbf{1 4}$ & $\mathbf{1}$ & $\mathbf{0}$ & $\mathbf{0}$ \\
\cline { 2 - 6 } & $\mathbf{9 3 \%}$ & $\mathbf{7 \%}$ & $\mathbf{0 \%}$ & $\mathbf{0 \%}$ \\
\hline
\end{tabular}

\section{Summary and Conclusions}

Opioid overdose is defined as a condition caused by the ingestion or absorption of opioids (CDC, 2013). Over-ingestion of the substance causes an individual's respiratory drive to shut down leading to death by apnea and hypoxemia. The number of overdose deaths in the United States has been increasing over the past few years to the point of an epidemic. One method that clinicians have used to combat this epidemic is increasing access of addicts to the opioid overdose reversal agent, Naloxone. Access to Naloxone has been a somewhat controversial approach.

A literature review was performed to address the controversial nature of these programs and to demonstrate the effect that allowing access to Naloxone has had on the number of overdose-related deaths. Prescribing Naloxone to the opioid addict through 
Overdose Education and Naloxone Distribution (ONE) programs as a means to prevent overdose is an example of harm reduction. Harm reduction involves decriminalizing or reducing stigma to substance abuse without requiring abstinence. According to the literature, harm reduction has been an effective way to combat the number of fatalities from opioid overdose. OEND programs are typically offered by trained professionals and involve teaching persons addicted to opioids and/or their friends and family how to recognize signs and symptoms of opioid overdose and how to safely and appropriately administer the medication to reverse the overdose. Based on initial program evaluations, OEND has been successful in reducing the number of overdose-related deaths (DoeSimkins et al, 2014). An educational program, aimed at nurses working on a medicalsurgical telemetry floor, was developed using W.K. Kellogg's Logic Model and Knowles' Theory of Adult Learning.

The developed educational program was offered to all RNs working on the identified medical-surgical telemetry floor. There were a total of 21 participants. The questionnaire contained 14 scenarios and asked the participants to identify whether the scenario contained symptoms consistent with those of opioid overdose and whether or not they would administer Naloxone to the individual based on the symptoms in that particular scenario. The rationale for the program was that medical-surgical nurses would be better educated and more familiar with how to recognize signs and symptoms of overdose after the education than they were beforehand. This would allow these nurses to offer the education to patients and families prior to discharge from the inpatient setting as patients who have undergone opioid detoxification while inpatient are at a far greater risk for overdose upon discharge due to their tolerance being lowered.

Due to schedule conflicts and heavy workload, only $15(71 \%)$ participants were able to attend the program. After completion, a link to the post-education survey was sent out to the participants with a one week timeline for completion. Emails reminders were sent out to participants mid-week and one day before the deadline. 
After the post-education questionnaire responses were received, results were analyzed to determine whether the teaching had been effective. The scenarios were broken down into two different categories: items containing symptoms consistent with opioid overdose/ administer Naloxone and items containing symptoms inconsistent with opioid overdose/ do NOT administer Naloxone. Mean scores were measured for each item for both the pre and post questionnaires. Upon analyzing the data, two conclusions can be made. The first conclusion was that the education was successful in teaching participants how to recognize the signs and symptoms of opioid overdose. When the results were examined between the pre and post surveys, there was improvement in all but one of the scenarios in the first category for both recognizing symptoms of overdose and knowledge about whether or not to administer Naloxone for the associated symptoms. In pre-education surveys, overall means for these items showed that $71.38 \%$ of the respondents answered the questions correctly and in the post surveys $84 \%$ of the items were answered correctly. In item 12a with the following symptoms, "Very slow or shallow breathing or not breathing at all, convulsions (seizures), severe sweating or shakes, eyes: pinpoint pupils, eyes rolled back, blue nails, toenails or fingernails, very slow, faint pulse or no pulse at all, no response to shaking, calling their name, pain (deep sleep)" $95 \%$ of respondents initially identified this correctly, but in the post survey, only $93 \%$ of respondents answered correctly. One explanation for this might be that convulsions or seizures were also taught as symptoms of cocaine overdose, which may have caused some confusion.

The second conclusion that was made from analyzing the results was that more time should be spent educating RNs on symptoms specifically not consistent with opioid overdose. In the pre-education surveys, $46.5 \%$ of participants were able to correctly identify that these scenarios contained symptoms of other types of drug overdose. In the post surveys, the results were $46.6 \%$ correct. The bigger discrepancy in these items involved whether or not the participants felt that Naloxone should be administered. Before 
the education, $90 \%$ of participants answered the questions correctly. Afterwards, $79.6 \%$ of respondents answered correctly. The explanation for this is most likely that a common question posed in each offered class was, "Is there any harm in administering Naloxone if the person is not experiencing an opioid overdose?" The general answer to this question was that there is no harm, which is what most likely influenced participants to be more liberal in administering Naloxone.

Overall, the project met the objectives which were for RNs to be more familiar with the signs and symptoms of opioid overdose and feeling confident when to administer Naloxone. Being able to recognize signs and symptoms of other types of drug overdose is not necessary. Naloxone can be safely administered to an individual whether or not they are experiencing overdose.

Limitations

There were many limitations in the execution of this project. The first limitation identified was that the four surveys rolled out to the same population of nurses within a week of the pre-education surveys being rolled out. These surveys were lost in the mix and it was difficult to recruit more participants. The next limitation was the large number of nurses who took new positions between the rollout of the surveys and the education being offered. Due to scheduling conflicts, the education was offered nearly 4 months after the surveys were first rolled out. This reduced the number of participants available to complete the education and the post-surveys. Ideally, the education would have consisted of a PowerPoint in a one hour time frame to appropriately deliver the information. Unfortunately, floor nurses do not have the time to dedicate to this type of learning and the program had to be delivered in a 20 minute timeframe. 
Recommendations and Implications for Advanced Practice Nursing

While the program did not improve outcomes for both recognition of opioid overdose and need to administer Naloxone, the education was proven to be effective for the more important of the two, recognition. Consistent with the literature, the OEND program helped individuals more accurately recognize the signs and symptoms of opioid overdose.

Alternative teaching could have created an interactive, online learning module. That would allow nurses to complete the education at a time more convenient for them. It would also allow for learning materials to be stored in an electronic database so that nurses could more easily access them in the future.

The results from this project were disseminated to the nurse managers during the morning meeting. The nurse managers delivered the information to their staff during monthly staff meetings. Results were also provided to the members of the Nurse Practice Council during their monthly committee meeting for consideration of project expansion to other units. A poster presentation was offered during the medical center's yearly Evidence Based Practice Conference. The project was presented at Rhode Island College.

\section{References}

Beletsky, L., Rich, J., \& Walley, A. (2012). Prevention of fatal overdose. Journal of the American Medical Association, 30(18), 1863-1864. Retrieved from 
http://prescribetoprevent.org/wp-content/uploads/JAMA-Viewpoint-BeletskyRich-Walley.pdf

Burton, J. K., \& Merrill, P. F. (1991). Needs assessment: Goals, needs and priorities. In L. J. Briggs, K. L. Gustafson, \& Tillman, M. H. (Eds.), Instructional Design Principles and applications. Englewood Cliffs, NJ: Educational Technology Publications.

Centers for Disease Control and Prevention (2013). Case definition: Opioids (Fentanyl, Etorphine or Others). Retrieved from http://www.bt.cdc.gov/agent/opioids/casedef.asp.

Centers for Disease Control and Prevention (2014, June 20). Notes from the field: Increase in Fentanyl-related overdose deaths - Rhode Island, November 2013March 2014. Retrieved from http://www.cdc.gov/mmwr/preview/mmwrhtml/mm6324a3.htm

Centers for Disease Control and Prevention. (2014). Prescription Drug Overdose in the United States: Fact Sheet. Retrieved from http://www.cdc.gov/homeandrecreationalsafety/overdose/facts.html

Doe-Simkins, M., Quinn, E., Xuan, Z., Sorensen-Alawad, A., Hackman, H., Ozonoff, A., \& Walley, A. (2014). Overdose rescues by trained and untrained participants and change in opioid use among substance-using participants in overdose education and naloxone distribution programs: A retrospective cohort study. BMC Public Health, 14297. doi:10.1186/1471-2458-14-297

Drug Policy Alliance (2014). Rhode Island Good Samaritan Overdose Prevention Act. 
Retrieved from http://www.drugpolicy.org/resource/ri-state-good-samaritanoverdose-prevention-act-\%C2\%A712251-\%E2\%80\%93-2012

Green, T. C., Heimer, R., \& Grau, L. E. (2008). Distinguishing signs of opioid overdose and indication for naloxone: An evaluation of six overdose training and naloxone distribution programs in the United States. Addiction, 103(6), 979-989. doi:10.1111/j.1360-0443.2008.02182.x

Institute of Medicine (2010). The future of nursing: Leading change, advancing health. Retrieved from http://iom.nationalacademies .org/ /media/Files/Report\%20Files/2010/TheFuture-of-Nursing/Future\%20of\%20Nursing\%202010\%20Recommendations.pdf

Keller, R., Frank-Bader, M., Beltran, K., Ascalon, M., \& L Bowar-Ferres, S. (2011). Peer education: An innovative approach for integrating standards into practice. Journal of Nursing Care Quality, 26(2), 120-127. doi:10.1097/NCQ.0b013e3181f63845

Knowles, M. S. (1970). The modern practice of adult education (Vol. 41). New York: New York Association Press.

Lee, N. (2013). Review of harm reduction (2nd ed.). Drug and Alcohol Review, 32(5), 552.

Marlatt, G., Larimer, M., \& Witkiewitz, K. (Eds.). (2012). Harm reduction. (2 ${ }^{\text {nd }}$ ed.): Pragmatic strategies for managing high-risk behaviors. New York, New York: The Guilford Press.

National Institutes for Health (2013). Opioid intoxication. Retrieved from http://www.nlm.nih.gov/medlineplus/ency/article/000948.htm

Oliva, E. (2014, July 14). Opioid overdose education and Naloxone distribution (OEND) 
To prevent opioid overdose [PowerPoint slides]. Retrieved from https://vaww.portal2.va.gov/sites/mentalhealth/OEND/_layouts/PowerPoint.aspx? $\underline{\text { PowerPointView=ReadingView\&PresentationId=/sites/mentalhealth/OEND/Reso }}$ urce\%20Library/Train\%20the\%20Trainer\%20PresentationOEND.pptx\&Source= https $\% 3 \mathrm{~A} \% 2 \mathrm{~F} \% 2 \mathrm{Fvaww} \% 2 \mathrm{Eportal} \% 2 \mathrm{Eva} \% 2 \mathrm{Egov} \% 2 \mathrm{Fsites} \% 2 \mathrm{Fmentalhealth} \%$ 2FOEND\%2FResource\%2520Library\%2FForms\%2FResource\%2520Library\%2 Easpx\&DefaultItemOpen=1\&DefaultItemOpen $=1$

Tatarsky, A., \& Marlatt, G. (2010). State of the art in harm reduction psychotherapy: An emerging treatment for substance misuse. Journal of Clinical Psychology, 66(2), $117-122$.

United States. Department of Veterans Affairs. Veterans Health Administration. (2014). Implementation of Opioid Overdose Education and Naloxone Distribution (OEND) to Reduce Risk of Opioid-Related Death (IL 10-2014-12). Washington DC: Petzel, R.

United States. Department of Veterans Affairs. VA Pharmacy and Benefits Management Service. (2014). Interim Recommendations for Issuing Naloxone Kits for the VA Overdose Education and Naloxone Distribution (OEND) Program. Washington

DC: Goodman, F.Veterans Affairs Palo Alto Healthcare System (2013). Opioid overdose education and naloxone distribution trainer's manual: Core competencies. Retrieved from https://vaww.cmopnational.va.gov/CR/MentalHealth/OEND/VABased\%20Materials/Training\%20Materials/10.2313\%200END\%20Trainer's\%20 Manual.pdf

Walley, A. Y., Ziming, X., Hackman, H., Quinn, E., Doe-Simkins, M., Sorensen-Alawad, 
A., \& Ozonoff, A. (2013). Opioid overdose rates and implementation of overdose education and nasal naloxone distribution in Massachusetts: Interrupted time series analysis. BMJ: British Medical Journal, 346(7894), 13. doi:10.1136/bmj.f174

Wilder, C., Brason, F., Clark, A., Galanter, M., Walley, A., \& Winstanley, E. (2014). Development and implementation of an opioid overdose prevention program within a preexisting substance use disorders treatment center. Journal of Addiction Medicine, 8(3), 164-169. doi:10.1097/ADM.0000000000000032

Williams, A. V., Marsden, J., \& Strang, J. (2014). Training family members to manage heroin overdose and administer naloxone: Randomized trial of effects on knowledge and attitudes. Addiction, 109(2), 250-259. doi:10.1111/add.12360

W.K. Kellogg Foundation (2004). Logic model development guide. Retrieved from http://www.smartgivers.org/uploads/logicmodelguidepdf.pdf 
Appendix A

OEND Interim Guidelines

\section{NALOXONE KITS AND NALOXONE AUTOINJECTORS \\ Recommendations for Issuing Naloxone Kits and Naloxone Autoinjectors for the VA Overdose Education and Naloxone Distribution (OEND) Program \\ October 2015 \\ VA Pharmacy Benefits Management Services, Medical Advisory Panel, and VISN Pharmacist Executives in collaboration with the VA OEND National Support and Development Work Group \\ The following recommendations are based on medical evidence, clinician input, and expert opinion. The content of the document is dynamic and will be revised as new information becomes available. Local adjudication should be used until updated guidance and/or CFU are developed by the National PBM. The purpose of this document is to assist practitioners in clinical decision-making, to standardize and improve the quality of patient care, and to promote cost-effective drug prescribing. \\ The drug Product Information should be consulted for detailed prescribing information. Also see Naloxone Autoinjector Abbreviated Review at www.pbm.va.gov.}

The VA Overdose Education and Naloxone Distribution (OEND) program is a harm reduction and risk mitigation initiative that aims to decrease opioid-related overdose deaths among VA patients The issuance of naloxone kits or autoinjectors constitutes just one component of the OEND program; opioid overdose prevention, recognition of opioid overdose and rescue response comprise other key components. While anyone may be educated and trained in these aspects of opioid overdoses, naloxone remains a medication obtainable only by prescription in most states in the U.S. Naloxone kit and autoinjector utilization and rates of opioid overdose and mortality will be tracked nationally in VA to evaluate the OEND program's performance. The PBM, MAP, and VPEs, in collaboration with the VA OEND National Support and Development Work Group, prepared the following recommendations to provide standardized guidance on the issuance of naloxone kits and autoinjectors under the VA OEND program. 


\section{CLINICAL RECOMMENDATIONS FOR OFFERING NALOXONE KITS AND NALOXONE AUTOINJECTORS}

A prescription is required for naloxone kits and naloxone autoinjectors.

Discuss naloxone as an opioid harm reduction / risk mitigation option with patient and/or family/carer and document the discussion in the patient's medical records.

Offer naloxone kits to Veterans prescribed or using opioids who are at increased risk for opioid overdose or whose provider deems, based on their clinical judgment, that the Veteran has an indication for a naloxone kit. See examples of candidates for naloxone kits below.

Offer naloxone autoinjectors to those who are candidates for naloxone kits AND are unable to demonstrate assembly and administration of the IM and IN 'kit' naloxone in a timely manner.

Examples of Candidates for Naloxone Kits include but are not limited to Veterans with the following:

- Opioid use disorder diagnosis

- Prescription opioid misuse

- Injection opioid use

- Likely to have an opioid overdose such as individuals who receive VA or non-VA care in these situations:

for opioid use disorder

Medication Assisted Treatment Program

Inpatient withdrawal management for opioid use disorder (particularly patients recently discharged from abstinence program) (which may provide care to injection opioid users)

HIV education / prevention program disorder treatment programs programs for opioid use disorder poisoning / overdose or intoxication) treatment for homeless Veterans for follow-up of recent opioid poisoning / overdose or intoxication)

Syringe access program

Outpatient and residential opioid use

Community meetings / Support group

Emergency departments (e.g., for opioid

Domiciliary care or community-based

Primary health care (e.g.,

Also refer to Error! Reference source not found. on page Error! Bookmark not defined. as a guide for evidence-based classification of OEND candidates. Error! Reference source not found. on page Error! Bookmark not defined. provides relative risks of opioid overdose deaths among Veterans prescribed opioids.

Nonveterans requesting naloxone should be directed to community-based OEND programs. A national locator is available at http://hopeandrecovery.org/locations/ .

Individuals in hospice / palliative care are likely NOT appropriate candidates for naloxone kits or autoinjectors. OEND should be considered on a case by case basis and not routinely in hospice / palliative care patients. 
Assessment Tools for Risk of Opioid-related Serious Toxicity or Overdose

- There are no published or fully validated tools available at this time that may be used to estimate patient risk for serious toxicity or overdose related to opioids.

- The manufacturer of naloxone autoinjector, Kaléo, is developing a tool that intends to estimate the probability of serious toxicity or overdose based on an index score based on the presence of various risk factors in patients prescribed opioids. The investigators identified the risk factors and retrospectively validated the tool using VHA administrative data.

- Guideline-concordant risk assessment tools for predicting opioid aberrant drug-related behavior or problematic substance use should be used as part of a comprehensive risk assessment of patients being treated for substance use disorders or chronic pain. These tools have not been shown to be useful for predicting opioid overdose; however, they may provide information that is important to consider in the overall risk assessment and management of the patient.

Educate and train the patient on the proper use, storage, administration and disposal of naloxone kits and needles and autoinjectors.

- Explain that naloxone combined with overdose education complement, but do not replace, safe and responsible opioid use.

- Emphasize the importance of being familiar with naloxone administration technique before an emergency arises.

- Advise the patient about the importance of friends, family members, partners, and carers being educated and trained on the proper use, potential harms and limitations of naloxone treatment. A list of resources for education and training is included in the naloxone kits. Patient education resources include the following:

- SAMHSA Opioid Overdose Prevention Toolkit: Contains safety advice for patients and resources for family members. http://store.samhsa.gov/product/Opioid-Overdose-Prevention-Toolkit/SMA13-4742

- Community-Based Overdose Prevention and Naloxone Distribution Program Locator: Identifies programs outside of the VA that distribute naloxone. http://hopeandrecovery.org/locations/

- Prescribe to Prevent: Patient resources and videos demonstrating overdose recognition and response, including naloxone administration. • http://prescribetoprevent.org/video/

- Optionally (but highly encouraged), also educate and train at least one patient-authorized acquaintance (i.e., one who is likely to witness opioid overdoses such as a friend, family member, partner or carer).

- Instruct the patient to inspect the naloxone solution for particulate matter or discoloration, and check the expiration date. Avoid exposure of naloxone to prolonged temperature variations below $68^{\circ}$ or above $77^{\circ} \mathrm{F}$. For example, do not store naloxone in a vehicle subject to extreme high or low temperature changes.

Issue a maximum of one naloxone kit ( 2 doses / kit) or autoinjector carton ( 2 doses / carton) per prescription. Prescriptions may be marked for one refill. 


\section{Naloxone Dosage and Administration}

\begin{tabular}{|c|c|c|}
\hline $\begin{array}{l}\text { Intramuscular (IM) } \\
\text { Naloxone Kit }\end{array}$ & $\begin{array}{l}\text { Intranasal (IN) } \\
\text { Naloxone Kit }\end{array}$ & $\begin{array}{l}\text { IM / Subcutaneous Naloxone } \\
\text { Autoinjector }\end{array}$ \\
\hline $\begin{array}{l}\text { - Inject } 0.4 \mathrm{mg} \text { in } 1 \mathrm{ml} \text { IM } \\
\text { (using vials), through } \\
\text { clothing if necessary } \\
\text { - } \quad \text { May repeat dose in 3-5 } \\
\text { minutes if no response } \\
\text { - } \quad \text { Dose may be repeated if } \\
\text { apnea or hypopnea recurs }\end{array}$ & $\begin{array}{l}\text { - Spray } 1 \mathrm{mg} \text { in } 1 \mathrm{ml} \text { in } \\
\text { each nostril using } \\
\text { atomizer device } \\
\text { (each syringe } \\
\text { contains } 2 \mathrm{mg} \text { in } 2 \\
\mathrm{ml} \text { ) } \\
\text { May repeat dose in } \\
3-5 \text { minutes if no } \\
\text { response } \\
\text { Dose may be } \\
\text { repeated if apnea or } \\
\text { hypopnea recurs }\end{array}$ & $\begin{array}{l}\text { Administer } 0.4 \mathrm{mg} \text { in } 0.4 \mathrm{ml} \text { into the } \\
\text { anterolateral aspect of the thigh, } \\
\text { through clothing if necessary } \\
\text { May repeat doses every } 2 \text { to } 3 \\
\text { minutes (each carton contains } 2 \\
\text { doses) }\end{array}$ \\
\hline
\end{tabular}

Use requests to renew naloxone kit or autoinjector prescriptions as an opportunity to determine the circumstances (e.g., kit or autoinjector was used for overdose, lost, confiscated, expired, etc.) and base decisions to renew any prescriptions for opioids on the discussion with the patient and reassessment of risk-benefit.

- Also use the discussion as an opportunity to engage the patient, re-assess risk-benefits, provide reeducation about overdoses, review Taking Opioids Responsibly (as applicable), consider opioid risk mitigation strategies, and modify treatment plans.

To aid in national tracking of OEND program performance, providers should document opioid poisonings/overdoses in the medical record using the following ICD-10-CM code guidance:

- Begin with DIAGNOSTIC CATEGORY T40, followed by a

- 3 digit EXTERNAL CAUSE code, followed by a

- $7^{\text {th }}$ character DESCRIBING ENCOUNTER

Because DIAGNOSTIC CATEGORY T40 denotes "Poisoning by, adverse effect of and underdosing of narcotics and psychodysleptics (hallucinogens)" broadly, it is important to use one of the opioid-related $\mathbf{3}$ digit EXTERNAL CAUSE codes to allow documentation of the specific agent involved (if known) and whether the event was unintentional, intentional, an assault, undetermined, or due to an adverse effect. The $7^{\text {th }}$ character DESCRIBING ENCOUNTER are suffix letters A or D (initial or subsequent encounter, respectively) or S (sequela; a complication or condition arising from the overdose event). See the Table below for opioid-related 3 digit external cause codes to be tracked nationally. 
Table 1. Three digit external cause codes (added to T40 Diagnostic category) for documentation/tracking of opioid poisonings/overdoses

\begin{tabular}{|l|l|l|l|l|l|}
\hline Poisoning by: & $\begin{array}{l}\text { Accidental } \\
\text { (unintentional) }\end{array}$ & $\begin{array}{l}\text { Intentional } \\
\text { self-harm }\end{array}$ & Assault & Undetermined & $\begin{array}{l}\text { Adverse } \\
\text { effect }\end{array}$ \\
\hline Opium & $\mathrm{T} 40.0 \mathrm{X} 1$ & $\mathrm{~T} 40.0 \mathrm{X} 2$ & $\mathrm{~T} 40.0 \mathrm{X} 3$ & $\mathrm{~T} 40.0 \mathrm{X} 4$ & $\mathrm{~T} 40.0 \mathrm{X} 5$ \\
\hline Heroin & $\mathrm{T} 40.1 \mathrm{X} 1$ & $\mathrm{~T} 40.1 \mathrm{X} 2$ & $\mathrm{~T} 40.1 \mathrm{X} 3$ & $\mathrm{~T} 40.1 \mathrm{X} 4$ & $\mathrm{~N} / \mathrm{A}$ \\
\hline Other opioids & $\mathrm{T} 40.2 \mathrm{X} 1$ & $\mathrm{~T} 40.2 \mathrm{X} 2$ & $\mathrm{~T} 40.2 \mathrm{X} 3$ & $\mathrm{~T} 40.2 \times 4$ & $\mathrm{~T} 40.2 \mathrm{X} 5$ \\
\hline Methadone & $\mathrm{T} 40.3 \mathrm{X} 1$ & $\mathrm{~T} 40.3 \mathrm{X} 2$ & $\mathrm{~T} 40.3 \mathrm{X} 3$ & $\mathrm{~T} 40.3 \times 4$ & $\mathrm{~T} 40.3 \mathrm{X} 5$ \\
\hline $\begin{array}{l}\text { Other synthetic } \\
\text { narcotics }\end{array}$ & $\mathrm{T} 40.4 \mathrm{X} 1$ & $\mathrm{~T} 40.4 \mathrm{X} 2$ & $\mathrm{~T} 40.4 \mathrm{X} 3$ & $\mathrm{~T} 40.4 \mathrm{X} 4$ & $\mathrm{~T} 40.4 \mathrm{X} 5$ \\
\hline $\begin{array}{l}\text { Unspecified } \\
\text { narcotics }\end{array}$ & $\mathrm{T} 40.601$ & $\mathrm{~T} 40.602$ & $\mathrm{~T} 40.603$ & $\mathrm{~T} 40.604$ & $\mathrm{~T} 40.605$ \\
\hline $\begin{array}{l}\text { Other } \\
\text { narcotics }\end{array}$ & $\mathrm{T} 40.691$ & $\mathrm{~T} 40.692$ & $\mathrm{~T} 40.693$ & $\mathrm{~T} 40.694$ & $\mathrm{~T} 40.695$ \\
\hline
\end{tabular}

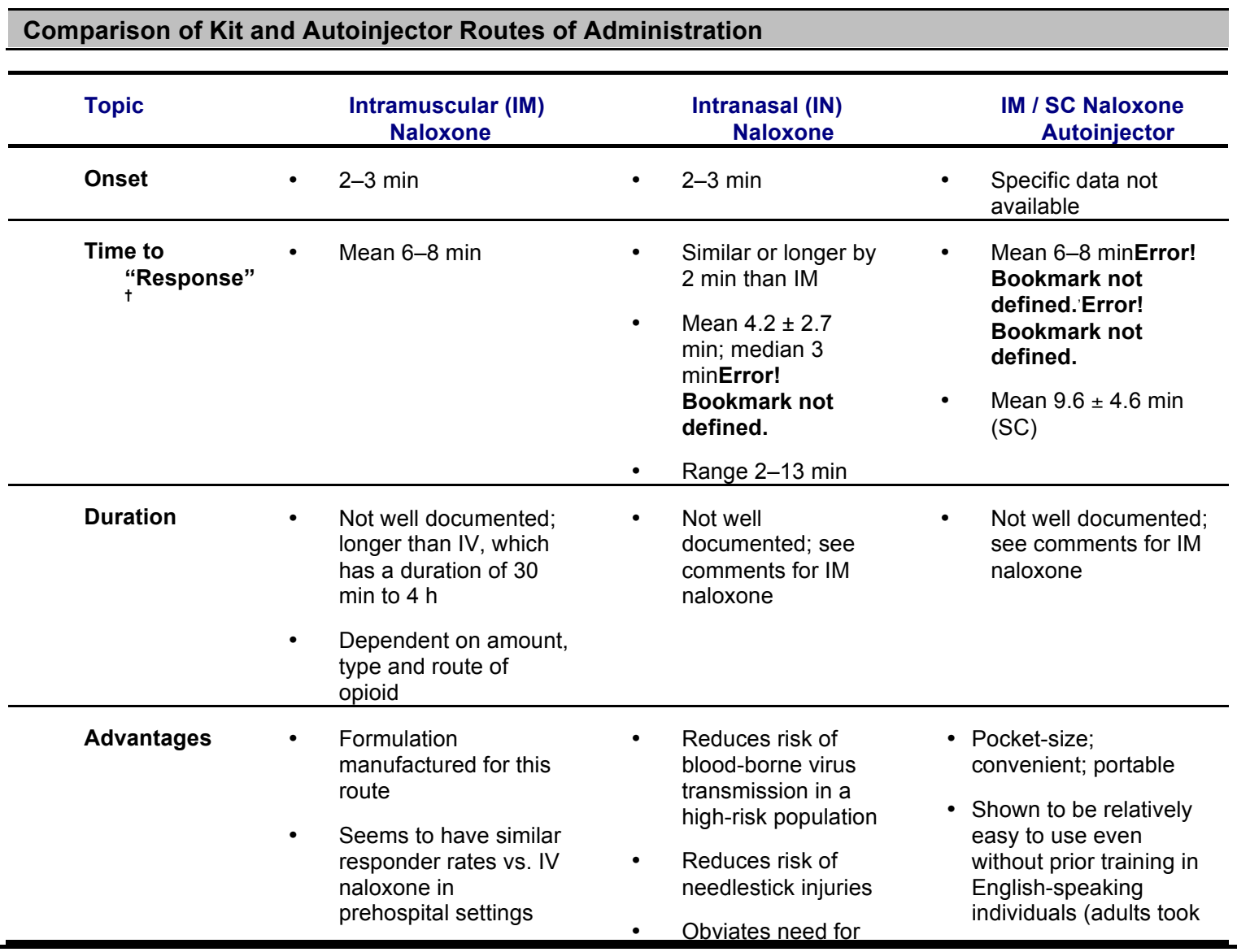




\begin{tabular}{|c|c|c|c|}
\hline & $\begin{array}{l}\text { - Involves fewer steps to } \\
\text { assemble } \\
\text { - } \quad \text { Simpler for some } \\
\text { people (e.g., those } \\
\text { familiar with using } \\
\text { injections) }\end{array}$ & $\begin{array}{l}\text { needle disposal } \\
\text { - } \quad \text { Easy access to } \\
\text { nares } \\
\text { - } \quad \text { May be preferred } \\
\text { by people with } \\
\text { aversion to needles } \\
\text { or injections }\end{array}$ & $\begin{array}{l}\text { on average about } 60 \\
\text { sec (range, } 30-160 \\
\text { sec) to administer } \\
\text { simulated injections. } \\
\text { - Retractable needle may } \\
\text { reduce accidental } \\
\text { needle sticks and risk } \\
\text { of blood-borne virus } \\
\text { transmission in a high- } \\
\text { risk population } \\
\text { - The needle is not seen } \\
\text { before, during or after } \\
\text { the injection; this may } \\
\text { be a desirable feature } \\
\text { for persons who have } \\
\text { an aversion to the sight } \\
\text { of needles. } \\
\text { - Discourages re-use of } \\
\text { the device by injection } \\
\text { drug users. } \\
\text { - The auto-injector } \\
\text { cannot be opened by } \\
\text { hand and modified; } \\
\text { opening it by using a } \\
\text { tool is difficult and } \\
\text { renders it } \\
\text { nonfunctional. } \\
\text { - Can be stored in a } \\
\text { wider temperature } \\
\text { range } \\
\text { The auto-injector case } \\
\text { provides adequate } \\
\text { protection from light }\end{array}$ \\
\hline Disadvantages & 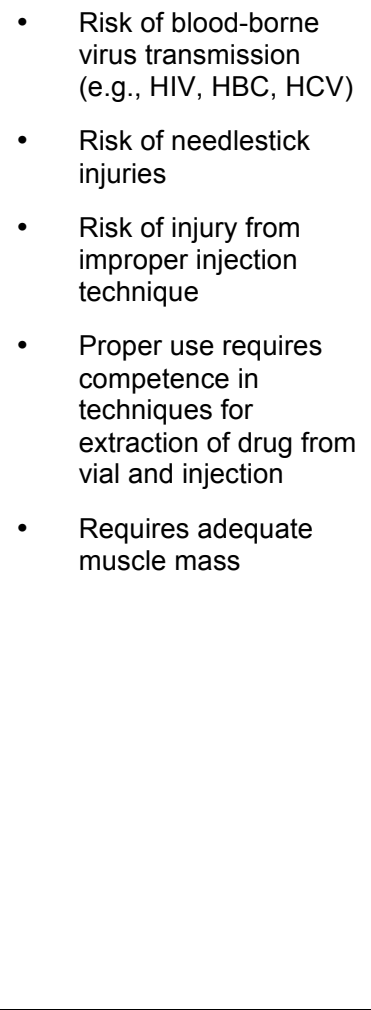 & $\begin{array}{l}\text { May have lower } \\
\text { bioavailability vs. } \\
\text { IM route } \\
\text { SimilarError! } \\
\text { Bookmark not } \\
\text { defined. or } \\
\text { slowerError! } \\
\text { Bookmark not } \\
\text { defined. onsets. } \\
\text { IM route } \\
\text { Similar or slightly } \\
\text { lower responder } \\
\text { rates vs. IM } \\
\text { naloxone } \\
\text { May be more likely } \\
\text { to require } \\
\text { supplemental } \\
\text { doses of } \\
\text { naloxoneError! } \\
\text { Bookmark not } \\
\text { defined. } \\
\text { Not manufactured } \\
\text { in a formulation for } \\
\text { this route (the } \\
\text { injectable form is } \\
\text { aerosolized) } \\
\text { Nasal } \\
\text { abnormalities (e.g. }\end{array}$ & $\begin{array}{l}\text { - If the voice instructions } \\
\text { fail, persons with poor } \\
\text { vision may have } \\
\text { difficulty reading the } \\
\text { label instructions } \\
\text { because of the small } \\
\text { font size } \\
\text { - Restriction to IM or SC } \\
\text { route of administration } \\
\text { - Needle length in } \\
\text { children less than } 1 \\
\text { year old; the skin } \\
\text { should be pinched to } \\
\text { prevent the needle from } \\
\text { contacting bone. If the } \\
\text { needle strikes bone, the } \\
\text { needle may be broken } \\
\text { or damaged and } \\
\text { delivery of drug may be } \\
\text { obstructed. } \\
\text { Lack of field testing by } \\
\text { Overdose Education } \\
\text { and Naloxone } \\
\text { Distribution (OEND) } \\
\text { programs. }\end{array}$ \\
\hline
\end{tabular}




\begin{tabular}{|c|c|c|c|}
\hline & & $\begin{array}{l}\text { epistaxis, trauma, } \\
\text { deformity, mucous) } \\
\text { and prior intranasal } \\
\text { drug use may } \\
\text { reduce } \\
\text { effectivenessError! } \\
\text { Bookmark not } \\
\text { defined. } \\
\text { Involves more } \\
\text { steps to assemble }\end{array}$ & \\
\hline $\begin{array}{l}\text { Other } \\
\text { Considerati } \\
\text { ons }\end{array}$ & $\begin{array}{l}\text { More common in U.S. } \\
\text { naloxone programs } \\
\text { - } \quad \text { Carpujects are a } \\
\text { potentially less costly } \\
\text { alternative to vials; } \\
\text { however, anecdotal } \\
\text { reports suggest that } \\
\text { the carpujects are } \\
\text { more difficult to } \\
\text { assemble, prices } \\
\text { fluctuate, and } \\
\text { carpujects have not } \\
\text { been field-tested. }\end{array}$ & $\begin{array}{l}\text { Off-label use; very } \\
\text { low-quality } \\
\text { evidence that IN } \\
\text { and IV/IM are } \\
\text { similar in clinical } \\
\text { effects } \\
\text { Associated with } \\
\text { successful opioid } \\
\text { overdose reversals } \\
\text { using } 1 \text { mg/ml per } \\
\text { naris (total } 2 \text { mg/2 } \\
\text { ml) and } 2 \text { mg/ml } \\
\text { (experimental). } \\
\text { Extent of nasal } \\
\text { absorption is } \\
\text { dependent on } \\
\text { mucosal surface } \\
\text { area coverage, } \\
\text { which is optimized } \\
\text { by using an } \\
\text { atomizer and } \\
\text { limiting quantity to } \\
1 \text { ml per naris. }\end{array}$ & $\begin{array}{l}\text { The 4-year battery life } \\
\text { for the voice } \\
\text { instructions exceeds } \\
\text { the product expiration. } \\
\text { - Whether training is } \\
\text { required in non-English } \\
\text { speaking individuals } \\
\text { has not been } \\
\text { evaluated; FDA } \\
\text { required human factor } \\
\text { testing in English } \\
\text { speaking individuals.. }\end{array}$ \\
\hline $\begin{array}{l}\text { Disposal of } \\
\text { Used or } \\
\text { Expired } \\
\text { Product }\end{array}$ & $\begin{array}{l}\text { Biohazard sharps } \\
\text { container }\end{array}$ & $\begin{array}{l}\text { Biohazard waste } \\
\text { container }\end{array}$ & $\begin{array}{l}\text { - Biohazard sharps } \\
\text { container }\end{array}$ \\
\hline
\end{tabular}




\section{Appendix B}

Information Email

Hello 6B nurses!

I am going to be bringing Opioid Overdose Education and Naloxone Distribution to 6B in the very near future. I am doing this as a part of my Master's thesis, so before providing you all with the education, I am going to ask each of you to fill out a pre-education survey:

Pre Education Survey Link

https://www.surveymonkey.com/r/JJHRQPK

It will only take a few minutes and it will help me gauge the educational needs of the unit. I will be asking you to fill out a post-education survey as well in a few weeks.

I would also like to ask if anyone would be interested in participating as a champion for this project. This would involve becoming a "trainer" for your peers who may not be able to attend the educational session I am giving and also assisting nurses who may have questions when they begin to utilize their training. (It also is a nice way to beef up your proficiencies.) Please email me if you are interested in this opportunity.

I will be visiting the units on the different shifts to try and recruit champions as well as survey responses. Thank you all for the incredible care you give our Veterans. I look forward to working with you soon!

\section{Emily Daniell, BSN RN}

Lead Nurse, Opiate Treatment Program

Providence VA Medical Center

$401-273-7100 \times 5824$

Appendix C

Submitted as both Pre Survey and Post Survey 


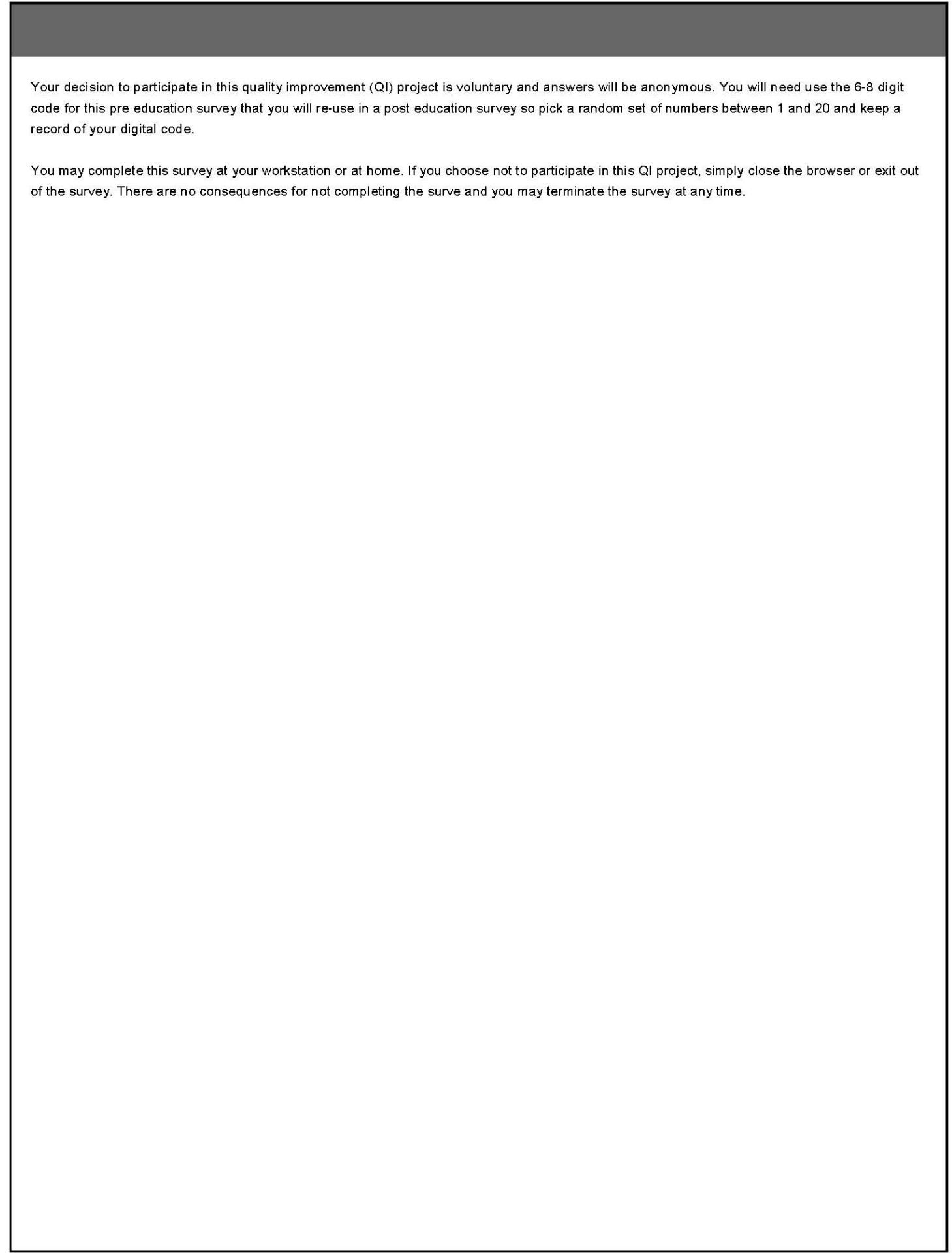




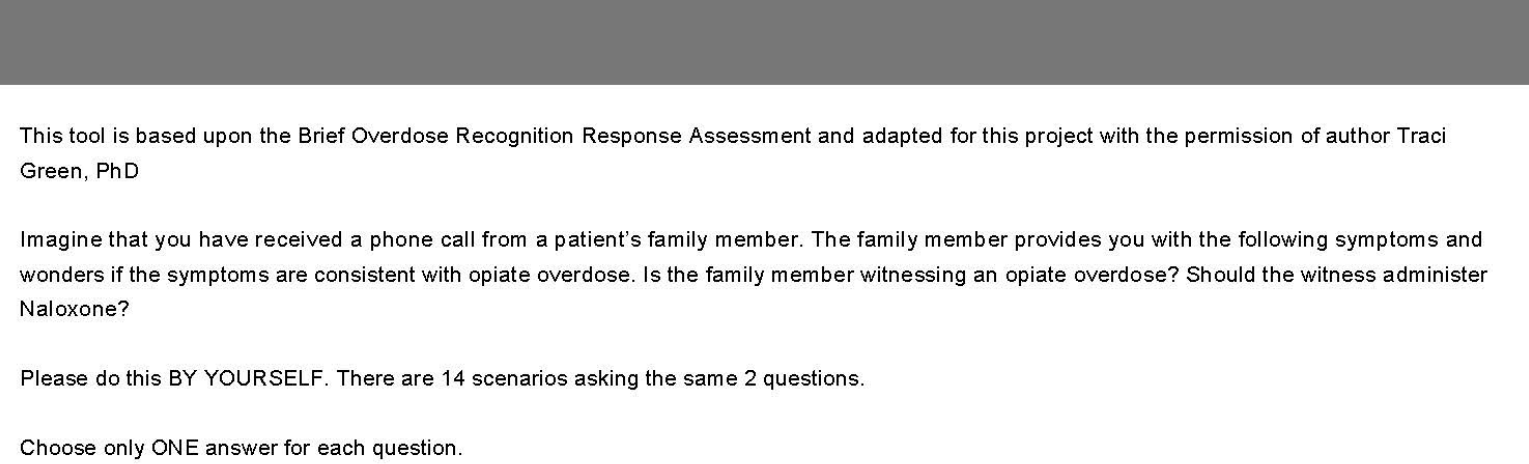

1. Please enter a 6-8 digit code for this pre education survey that you will re-use in a post education survey and enter in the space below. Save your number for your post-education survey.

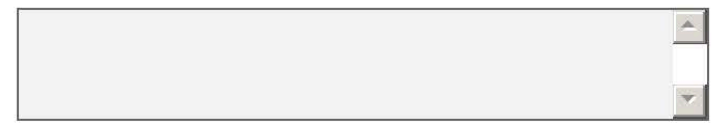

\section{Scenario 1:}

- Very slow or shallow breathing or not breathing at all

- Very slow, faint pulse or no pulse at all

- Fell unconscious

\section{Scenario 1a Question: Are the above symptoms:}

Consistent with signs of an opiate OD

Not signs of an $O D$

Unsure/not enough info

\section{Scenario 1b Question: Do the above symptoms suggest:}

Administer Naloxone

$\bigcirc$ Do NOT administer Naloxone

Scenario 2:

- Very slow or shallow breathing or not breathing at all

- Blue lips, toenails or fingernails

- Eyes: pin point pupils, eyes rolled back

- No response to shaking, calling their name, pain (deep sleep)

\section{Scenario 2a Question: Are the above symptoms:}

Consistent with signs of an opiate OD

$\bigcirc$ Not signs of an $O D$

Unsure/not enough info

\section{Scenario 2b Question: Do the above symptoms suggest:}

Administer Naloxone

Do NOT administer Naloxone 
Scenario 3:

- Restlessness, fidgety

\section{Scenario 3a Question: Are the above symptoms:}

Consistent with signs of an opiate OD
Not signs of an OD
Unsure/not enough info

\section{Scenario 3b Question: Do the above symptoms suggest:}

Administer Naloxone

$\bigcirc$ Do NOT administer Naloxone

Scenario 4:

- Numbness; couldn't feel anything

- Couldn't hear anything

- Felt weak

\section{Scenario 4a Question: Are the above symptoms:}

Consistent with signs of an opiate OD
Not signs of an OD
Unsure/not enough info

\section{Scenario 4b Question: Do the above symptoms suggest:}

Administer Naloxone

$\bigcirc$ Do NOT administer Naloxone

Scenario 5:

- Convulsions (seizures)

- Diminished vision

- Dizziness; confusion

\section{Scenario 5a Question: Are the above symptoms:}

$\bigcirc$ Consistent with signs of an opiate OD

Not signs of an OD

Unsure/not enough info

\section{Scenario 5b Question: Do the above symptoms suggest:}

Administer Naloxone

$\bigcirc$ Do NOT administer Naloxone

Scenario 6:

- Severe sweating or shakes

- Yawning

- Goose bumps

- Muscle pain/joint aches 
12. Scenario 6a Question: Are the above symptoms:

$\bigcirc$ Consistent with signs of an opiate $O D$

Not signs of an $O D$

Unsure/not enough info

13. Scenario 6b Question: Do the above symptoms suggest:

Administer Naloxone

Do NOT administer Naloxone

Scenario 7:

- Eyes: pinpoints pupils, eyes rolled back

- Couldn't speak

- Lost their voice

- Black out; fainted; unconscious

\section{Scenario 7a Question: Are the above symptoms:}

Consistent with signs of an opiate $O D$

$\bigcirc$ Not signs of an $O D$

Unsure/not enough info

\section{Scenario 7b Question: Do the above symptoms suggest:}

Administer Naloxone

$\bigcirc$ Do NOT administer Naloxone

Scenario 8

- Blue lips, toenails or fingertips

- No response to shaking, calling their name, pain (deep sleep)

\section{Scenario 8a Question: Are the above symptoms:}

$\bigcirc$ Consistent with signs of an opiate OD

Not signs of an $O D$

Unsure/not enough info

17. Scenario $8 \mathrm{~b}$ Question: Do the above symptoms suggest:

Administer Naloxone

Do NOT administer Naloxone

Scenario 9:

- Very slow or shallow breathing or not breathing at all

- Eyes: pinpoints pupils, eyes rolled back

- Very slow, faint pulse or no pulse at all

- Severe sweating or shakes

- No response to shaking, calling their name, pain (deep sleep)

- Blackout 
18. Scenario 9a Question: Are the above symptoms:

$\bigcirc$ Consistent with signs of an opiate OD

Not signs of an OD

Unsure/not enough info

19. Scenario 9b Question: Do the above symptoms suggest:

Administer Naloxone

Do NOT administer Naloxone

Scenario 10:

- Heart racing

\section{Scenario 10a Question: Are the above symptoms:}

$\bigcirc$ Consistent with signs of an opiate OD

Not signs of an OD

Unsure/not enough info

21. Scenario 10b Question: Do the above symptoms suggest:

Administer Naloxone

Do NOT administer Naloxone

Scenario 11:

- Very slow or shallow breathing or not breathing at all

- Very slow, faint pulse of no pulse at all

- Vomiting

\section{Scenario 11a Question: Are the above symptoms:}

Consistent with signs of an opiate OD

Not signs of an OD

Unsure/not enough info

\section{Scenario 11b Question: Do the above symptoms suggest:}

Administer Naloxone

$\bigcirc$ Do NOT administer Naloxone

Scenario 12:

- Very slow or shallow breathing or not breathing at all

- Convulsions (seizures)

- Severe sweating or shakes

- Eyes: pinpoint pupils, eyes rolled back

- Blue nails, toenails or fingernails

- Very Slow, faint pulse or no pulse at all

- No response to shaking, calling their name, pain (deep sleep) 
24. Scenario 12a Question: Are the above symptoms:

$\bigcirc$ consistent with signs of an opiate $O D$

$\bigcirc$ Not signs of an $O D$

Unsure/not enough info

25. Scenario 12b Question: Do the above symptoms suggest:

Administer Naloxone

DoNOT administer Naloxone

Scenario 13:

- Convulsions (seizures)

- Fear

26. Scenario 13a Question: Are the above symptoms:

consistent with signs of an opiate $O D$

Not signs of an $O D$

Unsure/not enough info

27. Scenario 13b Question: Do the above symptoms suggest:

Administer Naloxone

DoNOT administer Naloxone

Scenario 14:

- Very slow or shallow breathing or not breathing at all

- Very slow, faint pulse or no pulse at all

\section{Scenario 14a Question: Are the above symptoms:}

Consistent with signs of an opiate $O D$

Not signs of an $O D$

Unsure/not enough info

29. Scenario 14b Question: Do the above symptoms suggest:

Administer Naloxone

DoNOT administer Naloxone 


\section{Appendix D}

Adapted Brief Overdose and Recognition Response Assessment

\section{Scenario}

Imagine that you have received a phone call from a patient's family member. The family member provides you with the following symptoms and wonders if the symptoms are consistent with opiate overdose. Is the family member witnessing an opiate overdose? Should the witness administer Naloxone?

Please do this BY YOURSELF. There are 14 scenarios asking the same 2 questions.

Choose only ONE answer for each question.

\begin{tabular}{|c|c|}
\hline Scenario 1 & \\
\hline \multirow{4}{*}{$\begin{array}{l}\text { Very slow or shallow breathing or } \\
\text { not breathing at all } \\
\text { - Very slow, faint pulse or no pulse at all } \\
\text { - Fell unconscious }\end{array}$} & Are the symptoms: \\
\hline & $\begin{array}{l}\text { Consistent with signs of an opiate OD } \\
\mathbb{Z} \text { Not signs of an OD } \\
\mathbb{Z} \text { Unsure/not enough info }\end{array}$ \\
\hline & Do these symptoms suggest: \\
\hline & $\begin{array}{l}\mathbb{Z} \text { Administer Naloxone } \\
\mathbb{Z} \text { Do NOT administer Naloxone }\end{array}$ \\
\hline \multicolumn{2}{|l|}{ Scenario 2} \\
\hline \multirow{4}{*}{$\begin{array}{l}\text { Very slow or shallow breathing or } \\
\text { not breathing at all } \\
\text { - Blue lips, toenails or fingernails } \\
\text { - Eyes: pin point pupils, eyes rolled back } \\
\text { No response to shaking, calling their } \\
\text { name, pain (deep sleep) }\end{array}$} & Are the symptoms: \\
\hline & $\begin{array}{l}\text { Consistent with signs of an opiate OD } \\
\mathbb{Z} \text { Not signs of an OD } \\
\mathbb{Z} \text { Unsure/not enough info }\end{array}$ \\
\hline & Do these symptoms suggest: \\
\hline & $\begin{array}{l}\mathbb{Z} \text { Administer Naloxone } \\
\mathbb{Z} \text { Do NOT administer Naloxone }\end{array}$ \\
\hline \multicolumn{2}{|l|}{ Scenario 3} \\
\hline \multirow[b]{2}{*}{ - Restlessness, fidgety } & Are the symptoms: \\
\hline & $\begin{array}{l}\text { Consistent with signs of an opiate OD } \\
\mathbb{Z} \text { Not signs of an OD } \\
\mathbb{Z} \text { Unsure/not enough info }\end{array}$ \\
\hline
\end{tabular}




\begin{tabular}{|c|c|}
\hline & Do these symptoms suggest: \\
\hline & $\begin{array}{l}\mathbb{Z} \text { Administer Naloxone } \\
\mathbb{Z} \text { Do NOT administer Naloxone }\end{array}$ \\
\hline \multicolumn{2}{|l|}{ Scenario 4} \\
\hline \multirow{4}{*}{$\begin{array}{l}\text { - Numbness; couldn't feel anything } \\
\text { - Couldn't hear anything } \\
\text { - Felt weak }\end{array}$} & Are the symptoms: \\
\hline & $\begin{array}{l}\text { Consistent with signs of an opiate OD } \\
\mathbb{Z} \text { Not signs of an OD } \\
\mathbb{Z} \text { Unsure/not enough info }\end{array}$ \\
\hline & Do these symptoms suggest: \\
\hline & $\begin{array}{ll}\mathbb{Z} & \text { Administer Naloxone } \\
\mathbb{Z} & \text { Do NOT administer Naloxone }\end{array}$ \\
\hline \multicolumn{2}{|l|}{ Scenario 5} \\
\hline \multirow{4}{*}{$\begin{array}{l}\text { - Convulsions (seizures) } \\
\text { - Diminished vision } \\
\text { - Dizziness; confusion }\end{array}$} & Are the symptoms: \\
\hline & $\begin{array}{l}\text { Consistent with signs of an opiate OD } \\
\mathbb{Z} \text { Not signs of an OD } \\
\mathbb{Z} \text { Unsure/not enough info }\end{array}$ \\
\hline & Do these symptoms suggest: \\
\hline & $\begin{array}{ll}\mathbb{Z} & \text { Administer Naloxone } \\
\mathbb{Z} & \text { Do NOT administer Naloxone }\end{array}$ \\
\hline \multicolumn{2}{|l|}{ Scenario 6} \\
\hline \multirow{4}{*}{$\begin{array}{l}\text { - Severe sweating or shakes } \\
\text { - Yawning } \\
\text { - Goose bumps } \\
\text { - Muscle pain/joint aches }\end{array}$} & Are the symptoms: \\
\hline & $\begin{array}{l}\text { Consistent with signs of an opiate OD } \\
\mathbb{Z} \text { Not signs of an OD } \\
\mathbb{Z} \text { Unsure/not enough info }\end{array}$ \\
\hline & Do these symptoms suggest: \\
\hline & $\begin{array}{l}\mathbb{Z} \text { Administer Naloxone } \\
\mathbb{Z} \text { Do NOT administer Naloxone }\end{array}$ \\
\hline \multicolumn{2}{|l|}{ Scenario 7} \\
\hline \multirow{4}{*}{$\begin{array}{l}\text { - Eyes: pinpoints pupils, eyes rolled back } \\
\text { - Couldn't speak } \\
\text { - Lost their voice } \\
\text { - Black out; fainted; unconscious }\end{array}$} & Are the symptoms: \\
\hline & $\begin{array}{l}\text { Consistent with signs of an opiate OD } \\
\mathbb{Z} \text { Not signs of an OD } \\
\mathbb{Z} \text { Unsure/not enough info }\end{array}$ \\
\hline & Do these symptoms suggest: \\
\hline & $\begin{array}{ll}\mathbb{Z} & \text { Administer Naloxone } \\
\mathbb{Z} & \text { Do NOT administer Naloxone }\end{array}$ \\
\hline \multicolumn{2}{|l|}{ Scenario 8} \\
\hline \multirow{2}{*}{$\begin{array}{l}\text { Blue lips, toenails or fingertips } \\
\text { No response to shaking, calling } \\
\text { their name, pain (deep sleep) }\end{array}$} & Are the symptoms: \\
\hline & Consistent with signs of an opiate OD \\
\hline
\end{tabular}









\begin{tabular}{|c|c|}
\hline Scenario 12 & \\
\hline \multirow{4}{*}{$\begin{array}{l}\text { Very slow or shallow } \\
\text { breathing or not breathing at } \\
\text { all } \\
\text { - Convulsions (seizures) } \\
\text { - Severe sweating or shakes } \\
\text { - Eyes: pinpoint pupils, eyes rolled back } \\
\text { - Blue nails, toenails or fingernails } \\
\text { - Very Slow, faint pulse or no pulse at all } \\
\text { No response to shaking, calling their } \\
\text { name, pain (deep sleep) }\end{array}$} & Are the symptoms: \\
\hline & $\begin{array}{l}\text { Consistent with signs of an opiate OD } \\
\mathbb{Z} \text { Not signs of an OD } \\
\mathbb{Z} \text { Unsure/not enough info }\end{array}$ \\
\hline & Do these symptoms suggest: \\
\hline & $\begin{array}{ll}\mathbb{Z} & \text { Administer Naloxone } \\
\mathbb{Z} & \text { Do NOT administer Naloxone }\end{array}$ \\
\hline \multicolumn{2}{|l|}{ Scenario 13} \\
\hline \multirow{4}{*}{$\begin{array}{l}\text { - Convulsions (seizures) } \\
\text { - Fear }\end{array}$} & Are the symptoms: \\
\hline & $\begin{array}{l}\text { Consistent with signs of an opiate OD } \\
\mathbb{Z} \text { Not signs of an OD } \\
\mathbb{Z} \text { Unsure/not enough info }\end{array}$ \\
\hline & Do these symptoms suggest: \\
\hline & $\begin{array}{ll}\mathbb{Z} & \text { Administer Naloxone } \\
\mathbb{Z} & \text { Do NOT administer Naloxone }\end{array}$ \\
\hline \multicolumn{2}{|l|}{ Scenario 14} \\
\hline \multirow{4}{*}{$\begin{array}{l}\text { Very slow or shallow } \\
\text { breathing or not breathing at } \\
\text { all } \\
\text { - Very slow, faint pulse or no pulse at all }\end{array}$} & Are the symptoms: \\
\hline & $\begin{array}{l}\text { Consistent with signs of an opiate OD } \\
\mathbb{Z} \text { Not signs of an OD } \\
\mathbb{Z} \text { Unsure/not enough info }\end{array}$ \\
\hline & Do these symptoms suggest: \\
\hline & $\begin{array}{ll}\mathbb{Z} & \text { Administer Naloxone } \\
\mathbb{Z} & \text { Do NOT administer Naloxone }\end{array}$ \\
\hline
\end{tabular}

- Based upon the Brief Overdose Recognition Response Assessment and adapted for this project with the permission of author Traci Green, PhD 
Appendix E

Program Evalutation

\begin{tabular}{|l|l|}
\hline Title: & Opioid Overdose Education and Naloxone Distribution \\
\hline Date: & \\
\hline
\end{tabular}

INSTRUCTIONS: This evaluation form must be completed and submitted at the end of the session.

\begin{tabular}{|l|c|c|c|c|}
\hline Learner's Achievement of Each Objective & $\begin{array}{c}\text { Completely } \\
\text { Met } \\
\mathbf{4}\end{array}$ & $\begin{array}{c}\text { Mostly } \\
\text { Met } \\
\mathbf{3}\end{array}$ & $\begin{array}{c}\text { Partially } \\
\text { Met } \\
\mathbf{2}\end{array}$ & $\begin{array}{c}\text { Not } \\
\text { Met } \\
\mathbf{1}\end{array}$ \\
\hline Discuss the Epidemiology of Overdose. & & & & \\
\hline Describe the eligibility for Naloxone kits. & & & & \\
\hline Explain the process for order and prescriptions. & & & & \\
\hline $\begin{array}{l}\text { Describe the sources for Patient Education and } \\
\text { identify notes required for documentation. }\end{array}$ & & & & \\
\hline
\end{tabular}

How will the information provided be used to enhance or change your practice? BE SPECIFIC!

Rate the teaching expertise of each presenter.

\begin{tabular}{|l|l|l|l|l|}
\hline Presenter's Name: E. Daniell & $\begin{array}{l}\text { Excellen } \\
\mathbf{t}\end{array}$ & $\begin{array}{l}\text { Very } \\
\text { Good } \\
\mathbf{4}\end{array}$ & $\begin{array}{l}\text { Satisfactor } \\
\mathbf{y}\end{array}$ & $\begin{array}{l}\text { Poor } \\
\mathbf{2}\end{array}$ \\
\hline $\begin{array}{l}\text { Speaker's expertise contributed to the accomplishment of } \\
\text { the learning objectives }\end{array}$ & & & & \\
\hline $\begin{array}{l}\text { Teaching strategies/learning methods were utilized } \\
\text { effectively }\end{array}$ & & & \\
\hline $\begin{array}{l}\text { Instructional materials \&/or handouts were available and } \\
\text { supported the teaching methods }\end{array}$ & & & & \\
\hline Information updated me in my current practice & & & \\
\hline $\begin{array}{l}\text { The content \& objectives are appropriate and relevant to } \\
\text { your practice. }\end{array}$ & & & \\
\hline
\end{tabular}

Please rate your overall satisfaction with this program.
4 Excellent 》
3 Very Good 1]
2 Satisfactory $\rrbracket$
1 Poor $\rrbracket$ 